\title{
ENTROPIC EFFICIENCY OF ENERGY SYSTEMS
}

\author{
Vedat S. Arpaci and Ahmet Selamet \\ Department of Mechanical Engineering and Applied Mechanics, The University of Michigan, Ann Arbor, \\ Michigan 48109, U.S.A.
}

Received 26 February 1992

Abstract-Thermodynamic foundations of the thermal entropy production are rested on the concept of lost
heat, $(Q / T) \delta T$. The thermomechanical entropy production is shown to be in terms of the lost heat and the lost work as

$$
\delta \Pi=\frac{1}{T}\left[\left(\frac{Q}{T}\right) \delta T+\delta W_{\mathrm{L}}\right]
$$

where the second term in brackets denotes the lost (dissipated) work into heat.

The dimensionless number $\Pi_{s}$ describing the local entropy production $s^{\prime \prime \prime}$ in a quenched flame is related to

$$
\Pi_{s} \sim\left(P e_{D}^{0}\right)^{-2}
$$

where $\Pi_{s}=s^{\prime \prime \prime} \ell^{2} / k, \ell=\alpha / S_{\mathrm{u}}^{0}$ a characteristic length, $k$ thermal conductivity, $\alpha$ thermal diffusivity, $S_{\mathrm{u}}^{0}$ the adiabatic laminar flame speed at the unburned gas temperature, $P e_{\mathrm{D}}^{0}=S_{\mathrm{u}}^{0} D / \alpha$ the flame Peclet number, $D$ the quench distance. The tangency condition $\partial P e_{\mathrm{D}}^{0} / \partial \theta_{\mathrm{b}}=0$, where $\theta_{\mathrm{b}}=T_{\mathrm{b}} / T_{\mathrm{b}}^{0}, T_{\mathrm{b}}$ and $T_{\mathrm{b}}^{0}$ denoting respectively the burned gas (nonadiabatic) and adiabatic fiame temperatures, is related to an extremum in entropy production. The distribution of entropy production between the flame and burner is shown in terms of the burned gas temperature and the distance from burner.

A fundamental relation between the Nusselt number describing heat transfer in any (laminar, transition, turbulent) forced or buoyancy driven flow and the entropy production is shown to be

$$
N u \sim \Pi_{\mathrm{s}}^{1 / 2} .
$$

In view of this relation, the heat transfer from a pulse combustor becomes a measure for the entropic (thermal) efficiency of pulse combustion systems.

\section{CONTENTS}

$\begin{array}{lr}\text { Nomenclature } & 429 \\ \text { 1. Introduction } & 430 \\ \text { 2. Thermodynamic Foundations } & 431 \\ \text { 3. Local Entropy Production } & 433 \\ \text { 4. Turbulent Dissipation and Entropy Production } & 434 \\ \text { 5. A Thermal Microscale } & 435 \\ \text { 6. Heat Transfer and Entropy Production } & 435 \\ \text { 7. Quenched Flame } & 436 \\ \text { 8. Entropy Production in a Quenched Flame } & 437 \\ \text { 9. Entropy Production in a Boundary Layer } & 439 \\ \text { 10. Pulse Combustion Systems } & 441 \\ \text { 11. Conclusions } & 443\end{array}$

$\begin{array}{ll}\text { References } & 443\end{array}$

\section{NOMENCLATURE}

$B$ equilibrium intensity

$c$ speed of light

$c_{p}$ specific heat at constant pressure

$d$ thickness of reaction zone; change in a property

$D$ quench distance; hydraulic diameter

$E$ activation energy

$E_{\mathrm{b}}$ black body emissive power

$E_{\mathrm{n}}$ integro-exponential function of order $n=2,3,4$

$f$ Fanning friction factor $f_{\mathrm{i}}$ body force

$g$ function defined by Eqs (105) and (107)

$G$ Gibbs function; constant defined by Eq. (107)

$h$ heat transfer coefficient

$H$ enthalpy; heat transfer number

$J$ averaged intensity

$k$ thermal conductivity

$\ell$ a characteristic length

$\ell_{\mathrm{i}} \quad$ unit vector in $x_{\mathrm{i}}$

$\mathrm{Nu}$ Nusselt number

$p$ pressure

$P$ Planck number

$P e$ Peclet number

Pr Prandtl number 
$q$ heat flux

$q_{\mathrm{i}}$ heat flux in $x_{\mathrm{i}}$

$Q$ heat

$\mathrm{R}$ universal gas constant

Re Reynolds number

$s$ entropy/mass

$s^{\prime \prime \prime}$ rate of entropy generation/volume

$s_{\text {ij }}$ rate of deformation

$S$ entropy

$S_{u}$ laminar flame speed at unburned gas temperature

St Stanton number

$t$ time

$T$ temperature

$u$ internal energy/mass or volume; velocity; radiative pressure

$u^{\prime \prime \prime} \quad$ rate of energy generation/volume

$U$ internal energy

$U_{\mathrm{i}}$ mean velocity in $x$

$U_{0}$ velocity oscillation amplitude

$v$ specific volume

$v_{\mathrm{i}}$ velocity in $x_{\mathrm{i}}$

$V$ volume

$W$ work

$x, x_{i}$ coordinate axis

$y$ coordinate axis perpendicular to wall

\section{Greek Symbols}

$\alpha$ thermal diffusivity

$\gamma$ function defined by Eq. (107)

$\delta_{i j}$ Dirac delta function

$\Delta$ thermal boundary layer thickness

$\nabla^{2}$ Laplacian

$\varepsilon$ emissivity; turbulent dissipation

$\eta$ momentum sublayer thickness;

Kolmogorov scale; similarity variable

$\eta_{A}$ Batchelor scale

$\theta$ dimensionless temperature; turbulent temperature

$\Theta$ mean turbulent temperature; temperature defined by Eq. (107)

$\kappa$ absorption coefficient

$\lambda$ Taylor scale

$\mu$ dynamic viscosity

$v \quad$ kinematic viscosity

$\xi$ variable defined following Eq. (85)

$\Pi_{\mathrm{ij}}$ radiative tensor

$\Pi$ entropy production; entropy number

$\rho$ density

$\sigma$ Stefan-Boltzmann constant

$\tau$ optical thickness; dimensionless time; shear stress

$\tau_{\text {ij }}$ stress

$\chi$ weighted nongrayness

$\Psi$ entropy flow

$\Psi_{\mathrm{i}}$ entropy flux

$\omega$ frequency

$\omega_{0}$ cut-off frequency for frequency enhancement effects
Subscripts

b burned

$D$ quench distance

g generation

L lost

M mean; mechanical

P Planck mean

$R$ Rosseland mean

RMS root mean square

$s, S$ entropy

u unburned

w wall

$x$ local

$\theta$ thermal

$\infty$ ambient

I first order Ferguson and Keck model

II second order Ferguson and Keck model

III Clarke model

\section{Superscripts}

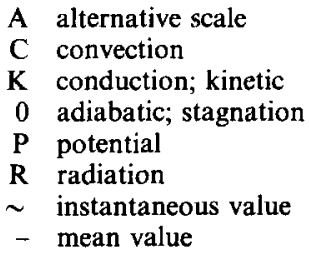

\section{INTRODUCTION}

The foundations of entropy production go back to Clausius and Kelvin studies on the irreversible aspects of the Second Law of Thermodynamics. Since then the theories based on these foundations have rapidly grown, first by the efforts of natural philosophers followed by astrophysicists, and later by those of applied scientists and engineers. However, the part of entropy production resulting from a temperature difference continues to remain untreated by the classical thermodynamics. This part of thermal (conduction and/or radiation) energy is the lost heat into entropy production.

Clearly, all forms of entropy production result from dissipative processes (involving mass, species, momentum and/or heat transfer, electromagnetic or nuclear transport). Less known is the fact that the dissipation may have a diffusive or hysteretic origin, the diffusion being directional and the hysteresis being cyclic. However, except for a few cases (such as strain hardening and the electromagnetic saturation), the majority of dissipative processes, including the dissipation of radiation, is of a diffusive nature, and is the concern of the present review.

The review consists of 11 sections: following this introduction, Section 2 explores the thermodynamic foundations of the entropy production; Section 3 develops the local entropy production in terms of the radiative stress; Section 4 relates the turbulent production of thermal energy to turbulent dissipation of thermal energy or, equivalently, to turbulent production of thermal entropy; Section 5 develops a thermal 
microscale based on this relation; Section 6 employs this scale in the establishment of the fundamental relation between turbulent heat transfer and entropy production; Section 7 applies the entropy production to flame quenching and interprets the tangency condition of laminar flame quenching by an extremum in entropy production; Section 8 deals with the distribution of entropy production in quenched laminar flames; Section 9 applies a thin gas model to the forced convection boundary layer over a horizontal flat plate and relates the wall entropy production to the local Nusselt number; Section 10 applies the entropy production to pulse combustion systems; and Section 11 concludes the study.

\section{THERMODYNAMIC FOUNDATIONS}

The concept of entropy production is now assumed well understood (see, for example, Arpaci, ${ }^{1,2}$ and Bird, Stewart, and Lightfoot ${ }^{3}$ ). The renewed interest in the concept is towards its utilization for engineering problems. Because of its size, no attempt is made here for a review of the literature (see Bejan ${ }^{4-6}$ for a review on the application to problems of fluid mechanics and heat transfer). Yet, an inspection of this literature reveals that, for a thermomechanical process, the concept of lost heat as opposed to that of lost work appears to remain untreated except for the recent studies by Arpaci, ${ }^{7-9}$ Arpaci and Selamet, ${ }^{10,11}$ and Selamet and Arpaci. ${ }^{12}$ The purpose of this section is to introduce the concept of lost heat, show the relation between this concept and the part of entropy production, and identify the effects of conduction and radiation by this production.

Consider a reciprocating engine. For each cycle of this engine, the First Law states

$$
Q_{1}-Q_{2}=W \text {. }
$$

The usual approach to the efficiency of this engine operating under a reversible cycle leads to a scale for the absolute temperature (Kelvin)

$$
\frac{Q_{1}}{Q_{2}}=\frac{T_{1}}{T_{2}},
$$

and to the definition of entropy flow,

$$
\Psi=\frac{Q}{T}
$$

The classical Second Law for an engine states that

$$
\frac{Q_{1}}{T_{1}} \leqslant \frac{Q_{2}}{T_{2}}
$$

or,

$$
\Psi_{1} \leqslant \Psi_{2},
$$

the equality being for a reversible cycle and the inequality being for an irreversible cycle.

This inequality suggests, from the view of a balance principle, an entropy production $\Pi$ which is a measure

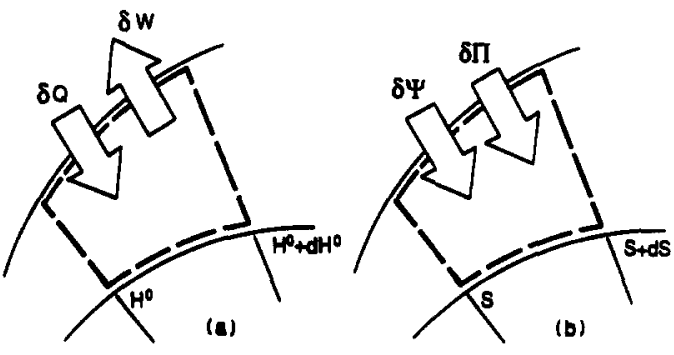

Fig. 1. Two laws for a differential control volume.

for the lost (irreversibly dissipated) energy. In terms of this production, the Second Law for any (reversible or irreversible) cycle may be expressed as

$$
\Psi_{2}-\Psi_{1}=\Pi
$$

For a reversible cycle

$$
\Pi=0
$$

and

$$
\Psi_{1}=\Psi_{2}=\text { Constant }
$$

which is identical to Eq. (2).

To illustrate the concept of lost energy further, consider a thermomechanical process through an infinitesimal control volume. The Fist Law applied to this control volume gives (Fig. la)

$$
\mathrm{d} H^{0}=\delta Q-\delta W,
$$

where

$$
H^{0}=U+p V+U_{\mathrm{K}}+U_{\mathrm{P}}
$$

is the stagnation enthalpy, $V$ the volume, $U_{\mathrm{K}}$ and $U_{\mathrm{P}}$ the kinetic and potential energies. Now, recall the definition of entropy flow (Eq. 3) and, express heat flow in terms of entropy flow,

$$
\delta Q \equiv \delta(T \Psi)
$$

or, explicitly,

$$
\delta Q=T \delta \Psi+\Psi \delta T,
$$

or,

$$
\delta Q=\delta Q_{\mathrm{s}}+\delta Q_{\mathrm{L}}
$$

$\delta Q_{\mathrm{s}}$ being the entropical part of heat explicit in the Second Law and $\delta Q_{\mathrm{L}}$ is the dissipated or lost heat into entropy. After a sign change, let $\delta W$ be split, in a similar manner to $\delta Q$, as*

$$
\delta W=-\left(\delta W_{M}+\delta W_{L}\right),
$$

where $\delta W_{M}$ is the part of mechanical work balanced in the mechanical energy and $\delta W_{\mathrm{L}}$ is the part dissipated or lost work into heat. Then, Eq. (8) becomes

$$
\begin{gathered}
\mathrm{d}\left(U+U_{\mathrm{K}}+U_{\mathrm{p}}\right)=\delta\left(Q_{\mathrm{S}}+Q_{\mathrm{L}}\right) \\
-\mathrm{d}(p V)+\delta\left(W_{\mathrm{M}}+W_{\mathrm{L}}\right)
\end{gathered}
$$

(with the sign change introduced in Eq. 13 the work

\footnotetext{
* The explicit tensorial form of $\delta W$ is left to Section 3.
} 

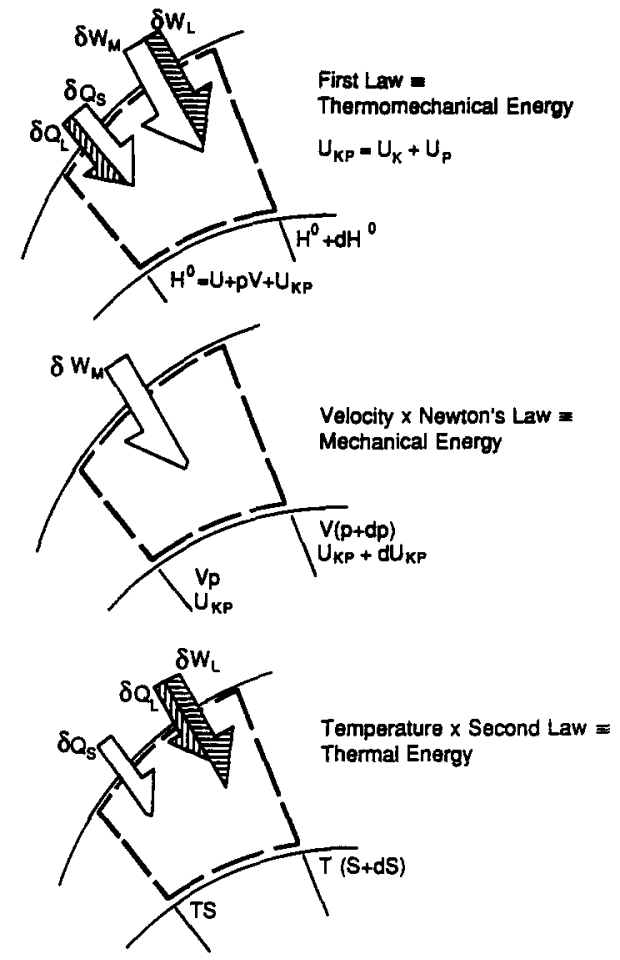

Fig. 2. First Law - Velocity $\times$ Newton's Law - Temperature $\times$ Second Law.

terms now reflect the opposite sign convention for pressure and shear stress).

The mechnical energy balance, obtained either by eliminating thermal effects from Eq. (14) or from the mechanical energy associated with Newton's Law, is

$$
\mathrm{d}\left(U_{\mathrm{K}}+U_{\mathrm{P}}\right)=-V \mathrm{~d} p+\delta W_{\mathrm{M}} .
$$

Note that $\delta W_{\mathrm{L}}$, being dissipated into heat, is a thermal term. Also, $p \mathrm{~d} V$ reversibly affects the internal (thermal) energy. As is well known, Eq. (15) is reduced to the Bernoulli equation for steady, incompressible and inviscid flow.

The Second Law (proposed) for the control volume (Fig. 1b) is

$$
\mathrm{d} S=\delta \Psi+\delta \Pi .
$$

For a reverisble process, $\delta \Pi=0, T=$ Constant, and Eq. (16) is reduced to the usual form of the Second Law,

$$
\mathrm{d} S=\frac{\delta Q}{T} .
$$

Now, for a thermomechanical process, consider the energy difference (Fig. 2)

First law - Mechanical Energy - T(Second Law), or,

$$
\text { (Total - Mechanical - Thermal) Energy }
$$

which, in terms of Eqs (14), (15) and (16), yields

$$
\mathrm{d} U+p \mathrm{~d} V-T \mathrm{~d} S=\delta Q_{\mathrm{L}}+\delta W_{\mathrm{L}}-T \delta \Pi,
$$
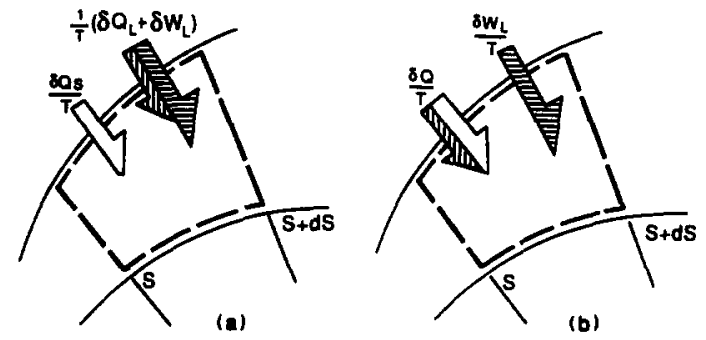

Fig. 3. Two alternatives of second law for a differential control volume.

or,

$$
\mathrm{d} G=\delta Q_{\mathrm{L}}+\delta W_{\mathrm{L}}-T \delta \Pi .
$$

Under local thermodynamic equilibrium,

$$
G=U+p V-T S
$$

defines the Gibbs function, and

$$
\mathrm{d} G=0,
$$

or, because of locally uniform $p$ and $T$,

$$
\mathrm{d} U=T \mathrm{~d} S-p \mathrm{~d} V .
$$

Then

$$
\delta \Pi=\frac{1}{T}\left(\delta Q_{\mathrm{L}}+\delta W_{\mathrm{L}}\right)
$$

Now, the Second Law given by Eq. (16) may be given alternative forms in terms of the lost heat and work as

$$
\mathrm{d} S=\delta \Psi+\frac{1}{T}\left(\delta Q_{\mathrm{L}}+\delta W_{\mathrm{L}}\right),
$$

or, in view of

$$
\delta Q_{\mathrm{s}}=T \delta \Psi,
$$

as (Fig. 3a)

$$
\mathrm{d} S=\frac{\delta Q_{\mathrm{S}}}{T}+\frac{1}{T}\left(\delta Q_{\mathrm{L}}+\delta W_{\mathrm{L}}\right),
$$

or, in view of Eq. (12), as (Fig. 3b)

$$
\mathrm{d} S=\frac{\delta Q}{T}+\frac{\delta W_{\mathrm{L}}}{T} .
$$

The explicit forms of $\delta Q_{\mathrm{L}}$ and $\delta W_{\mathrm{L}}$ will be given in the next section which deals with the rate of First and Second Laws of Thermodynamics.

When the First Law includes all (heat, work, radiative, electromagnetic, chemical and nuclear) forms of energy, Eq. (23) is generalized to

$$
\begin{gathered}
\text { Entropy production }= \\
\frac{1}{T} \text { (All forms of lost energy) }
\end{gathered}
$$

and Eq. (24) becomes

$\mathrm{d} S=\delta \Psi+\frac{1}{T}$ (All forms of lost energy), 
or, with the definition of

Lost energy (except for heat) $\equiv$ Dissipated energy into heat,

becomes

$$
\mathrm{d} S=\frac{\delta Q}{T}+\frac{1}{T} \text { (Energy dissipation into heat). }
$$

As already mentioned in the introduction, only the diffusive dissipation is the concern of this review.

Finally, let the internal energy, heat and work associated with the optical limit of electromagnetics or the gas radiation be $U^{\mathrm{R}}, Q^{\mathrm{R}}$ and $\boldsymbol{W}^{\mathrm{R}}$, respectively. As is well known

$$
U^{\mathrm{R}} \ll U, Q^{\mathrm{R}} \sim Q^{\mathrm{K}}, W^{\mathrm{R}} \ll W,
$$

provided the characteristic transport velocity remains much less than the velocity of light. Then, under the influence of radiation,

$$
Q=Q^{\mathrm{K}}+Q^{\mathrm{R}}
$$

$Q^{\mathrm{K}}$ being the heat flow by conduction.

\section{LOCAL ENTROPY PRODUCTION}

The entropy production discussed in Section 2 is extended here to moving media which requires as well the consideration of the momentum balance. For the Stokesean fluid, this balance in terms of the usual nomenclature is

$$
\rho \frac{D v_{\mathrm{i}}}{D t}=-\frac{\partial p}{\partial x_{\mathrm{i}}}+\frac{\partial \tau_{\mathrm{ij}}}{\partial x_{\mathrm{j}}}+\rho f_{\mathrm{i}} .
$$

In terms of the entropy flux,

$$
\Psi_{\mathrm{i}}=\frac{q_{\mathrm{i}}}{T},
$$

the entropy balance (the rate of Second Law balanced by the rate of local entropy production) is

$$
\rho \frac{D s}{D t}=-\frac{\partial \Psi_{i}}{\partial x_{i}}+s^{\prime \prime \prime}
$$

where $s^{\prime \prime \prime}$ denotes the local entropy production. Also, the conservation of total (thermomechanical) power (or the rate of First Law) including the heat flux expressed in terms of the entropy flux,

$$
\frac{\partial q_{\mathrm{i}}}{\partial x_{\mathrm{i}}} \equiv \frac{\partial}{\partial x_{\mathrm{i}}}\left(\Psi_{\mathrm{i}} T\right)=T \frac{\partial \Psi_{\mathrm{i}}}{\partial x_{\mathrm{i}}}+\Psi_{\mathrm{i}} \frac{\partial T}{\partial x_{\mathrm{i}}},
$$

is

$$
\begin{aligned}
\rho \frac{D}{D t}(u+ & \left.\frac{1}{2} v_{\mathrm{i}}^{2}\right)=-\frac{\partial}{\partial x_{\mathrm{i}}}\left(\Psi_{\mathrm{i}} T\right)-\frac{\partial}{\partial x_{\mathrm{i}}}\left(p v_{\mathrm{i}}\right) \\
& +\frac{\partial}{\partial x_{\mathrm{j}}}\left(\tau_{\mathrm{ij}} v_{\mathrm{i}}\right)+\rho f_{\mathrm{i}} v_{\mathrm{i}}+u^{\prime \prime \prime} .
\end{aligned}
$$

Now, the fundamental difference of power,

Rate of Total energy - (Momentum $)_{i} v_{i}$

- (Rate of Entropy)T, or,

$$
\text { Rate of (Total - Mechanical - Thermal) energy }
$$

leads, in terms of Eqs (30), (32), (34) and the conservation of mass,

$$
\frac{D \rho}{D t}+\rho \frac{\partial v_{\mathrm{i}}}{\partial x_{\mathrm{i}}}=0
$$

to

$$
\begin{gathered}
\rho\left(\frac{D u}{D t}-T \frac{D s}{D t}+p \frac{D v}{D t}\right)=-\Psi_{\mathrm{i}} \frac{\partial T}{\partial x_{\mathrm{i}}} \\
+\tau_{\mathrm{ij}} s_{\mathrm{ij}}+u^{\prime \prime \prime}-T s^{\prime \prime \prime}
\end{gathered}
$$

where $s_{\mathrm{ij}}$ is the rate of deformation. For a reversible process, all forms of dissipation vanish, and

$$
\frac{D u}{D t}-T \frac{D s}{D t}+p \frac{D v}{D t}=0
$$

which is the Gibbs Thermodynamic relation. For an irreversible process, Eq. (38) continues to hold provided the process can be assumed in local equilibrium. Then, Eq. (37) gives the rate of local entropy production

$$
s^{\prime \prime \prime}=\frac{1}{T}\left[-\Psi_{\mathrm{i}}\left(\frac{\partial T}{\partial x_{\mathrm{i}}}\right)+\tau_{\mathrm{ij}} s_{\mathrm{ij}}+u^{\prime \prime \prime}\right],
$$

where the first term in brackets denotes the dissipation of thermal energy into entropy (lost heat), the second term denotes the dissipation of mechanical energy into heat (lost work), and the third term denotes the dissipation of any (except for thermomechanical) energy into heat. When radiation is appreciable, $q_{\mathrm{i}}$ denotes the total flux involving the sum of conductive flux and radiative flux,

$$
q_{\mathrm{i}}=q_{\mathrm{i}}^{\mathrm{K}}+q_{\mathrm{i}}^{\mathrm{R}} .
$$

In terms of the radiative stress $\Pi_{\mathrm{ij}}$ based on the specular moments of the transfer equation, the radiative flux of Eq. (40) becomes

$$
q_{\mathrm{i}}^{\mathbf{R}}=-\frac{1}{\kappa_{\mathrm{R}}} \frac{\partial \Pi_{\mathrm{ij}}}{\partial x_{\mathrm{j}}},
$$

and can be interpreted as a generalized diffusion process for any optical thickness. A procedure for the evaluation of $\Pi_{i j}$ in terms of the Wallis Integrals is described in Unno and Spiegel. ${ }^{13}$ After lengthy manipulations, this procedure leads to

$$
\Pi_{\mathrm{ij}}=\sum_{n=0}^{\infty} \frac{\nabla^{2 n-2}\left(2 n \partial_{\mathrm{i}} \partial_{\mathrm{j}}+\nabla^{2} \delta_{\mathrm{ij}}\right) B}{\kappa_{\mathrm{M}}^{2 n}(2 n+1)(2 n+3)},
$$

where $B=4 E_{\mathrm{b}}, E_{\mathrm{b}}=\sigma T^{4}$ being the Stefan-Boltzmann law, $\kappa_{\mathrm{M}}=\left(\kappa_{\mathrm{P}} \kappa_{\mathrm{R}}\right)^{1 / 2}$ the mean absorption coefficient, and $\partial_{\mathrm{i}}=\partial / \partial x_{\mathrm{i}}$ and $\partial_{\mathrm{j}}=\partial / \partial x_{\mathrm{j}}$ are used for notational convenience. The same result may be found also in earlier works (see, for example, Milne ${ }^{14}$ ). The formal similarity of Eq. (42) to the Hookean constitution for elastic solids should be noted (see Arpaci ${ }^{15}$ ). 


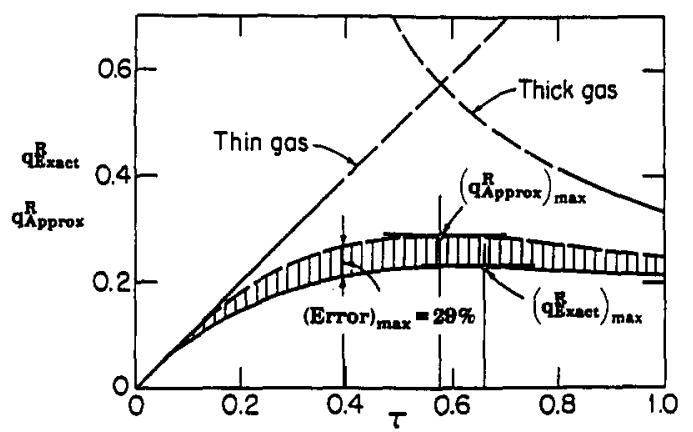

FIG. 4. Exact and approximate radiative fluxes.

An alternative form for this stress may be given in terms of the isotropic radiative pressure $u^{R}$. First, invoking the assumption of isotropy,

$$
\frac{1}{c} \Pi_{\mathrm{ij}}=\frac{1}{3} u^{\mathrm{R}} \delta_{\mathrm{ij}}=-p \delta_{\mathrm{ij}},
$$

where $p$ is the (isotropic) pressure of radiation and $c$ is the speed of light. Then, from the trace of $\Pi_{i j}$, noting that $\ell_{\mathrm{k}} \ell_{\mathrm{k}}=1$,

$$
\Pi_{\mathrm{kk}}=J=\sum_{n=0}^{\infty}\left(\frac{\nabla^{2}}{\kappa_{M}^{2}}\right)^{n} \frac{B}{(2 n+1)} .
$$

Now, in a manner similar to the incorporation of the isotropic pressure into the development of viscous stress from elastic stress, (see, for example, Arpaci and Larsen $^{2}$ ), adding the identity

$$
\frac{1}{3} J \delta_{\mathrm{ij}}-\frac{1}{3} \Pi_{\mathrm{kk}} \delta_{\mathrm{ij}}=0
$$

to Eq. (42), the $\Pi_{\mathrm{ij}}$-tensor may be rearranged in terms of the radiation pressure,

$\Pi_{\mathrm{ij}}=\frac{1}{3} J \delta_{\mathrm{ij}}+\sum_{n=0}^{\infty} \frac{2 n \nabla^{2 n-2}\left(\partial_{\mathrm{i}} \partial_{\mathrm{j}}-\frac{1}{3} \nabla^{2} \delta_{\mathrm{ij}}\right) B}{\kappa_{\mathrm{M}}^{2 n}(2 n+1)(2 n+3)}$.

The formal similarity of Eq. (46) to the viscous (Stokesean) stress and the electromagnetic (Maxwell) stress should be noted (see Arpaci ${ }^{15}$ ). This similarity is to be expected in view of the assumed isotropy for the elastic, viscous and electromagnetic continua (see, for example, Stratton ${ }^{16}$ and Prager ${ }^{17}$ ). The use of the first term of Eq. (46) in place of Eq. (42) is the well-known Eddington approximation which leads to a diffusive heat flux,

$$
q_{\mathrm{i}}^{\mathrm{R}}=-\frac{1}{3 \kappa_{\mathrm{R}}} \frac{\partial J}{\partial x_{\mathrm{i}}},
$$

for any optical thickness. The maximum deviation of this flux from the exact flux given by Eq. (41) is about $29 \%$ at $\tau=1 / \sqrt{3}$ (Fig. 4; Arpaci $^{15}$ ), $\tau$ being the optical thickness.

In terms of the usual conductive constitution and the radiative constitution given by Eq. (41), the rate of local entropy production is found to be

$$
\begin{gathered}
s^{\prime \prime \prime}=\frac{1}{T} \\
\times\left[\frac{1}{T}\left(\mathbf{k} \frac{\partial T}{\partial x_{\mathrm{i}}}+\frac{1}{\kappa_{\mathrm{R}}} \frac{\partial \Pi_{\mathrm{ij}}}{\partial x_{\mathrm{j}}}\right)\left(\frac{\partial T}{\partial x_{\mathrm{i}}}\right)+\tau_{\mathrm{ij}} s_{\mathrm{ij}}+u^{\prime \prime \prime}\right]
\end{gathered}
$$

whose radiative part needs to be related to temperature through Eqs (42) or (46). Also, the considerations of only the first term of Eq. (46) yields

$$
\begin{gathered}
s^{\prime \prime \prime}=\frac{1}{T} \\
\times\left[\frac{1}{T}\left(\mathbf{k} \frac{\partial T}{\partial x_{\mathrm{i}}}+\frac{1}{3 \kappa_{\mathrm{R}}} \frac{\partial J}{\partial x_{\mathrm{i}}}\right)\left(\frac{\partial T}{\partial x_{\mathrm{i}}}\right)+\tau_{\mathrm{ij}} s_{\mathrm{ij}}+u^{\prime \prime \prime}\right]
\end{gathered}
$$

whose radiative part is Eddington approximated and needs to be coupled with

$$
\left(\nabla^{2}-3 \kappa_{\mathrm{M}}^{2}\right) J=-12 \kappa_{\mathrm{M}}^{2} E_{\mathrm{b}}
$$

(see, for example, Arpaci and Gözüm ${ }^{18}$ ). The next section relates the entropy production to the turbulent thermal dissipation which is a measure for the entropic (thermal) efficiency of turbulent flows and systems.

\section{TURBULENT DISSIPATION AND ENTROPY PRODUCTION}

Consider an incompressible turbulent flow. Let the instantaneous turbulent temperature be decomposed into a mean value and fluctuations,

$$
\tilde{\theta}=\Theta+\theta .
$$

A positive measure for these fluctuations is $\overline{\theta^{2}}$. The equation governing $\overrightarrow{\theta^{2}}$ may be obtained in a manner similar to the equation for the balance of kinetic energy (see, for example, Arpaci and Larsen ${ }^{2}$ ). The result is

$$
U_{\mathrm{i}} \frac{\partial}{\partial x_{\mathrm{i}}}\left(\frac{1}{2} \overline{\theta^{2}}\right)=-\frac{\partial}{\partial x_{\mathrm{i}}}\left(\mathscr{D}_{\theta}\right)_{\mathrm{i}}+\mathscr{P}_{\theta}-\varepsilon_{\theta}
$$

where

$$
\left(\mathscr{D}_{\theta}\right)_{\mathrm{i}}=\frac{1}{2} \overline{\theta^{2} u_{\mathrm{i}}}-\alpha \frac{\partial}{\partial x_{\mathrm{i}}} \frac{1}{2} \overline{\theta^{2}}
$$

is the mean thermal transport (turbulent thermal flux),

$$
\mathscr{P}_{0}=-\overline{u_{\mathrm{i}} \theta} \frac{\partial \Theta}{\partial x_{\mathrm{i}}}
$$

is the thermal production, and

$$
\rho c_{\mathrm{p}} \varepsilon_{\theta}=-\overline{q_{\mathrm{i}}\left(\frac{\partial \theta}{\partial x_{\mathrm{i}}}\right)}
$$

is the thermal dissipation.

For homogeneous fluctuations, Eq. (51) yields

$$
\mathscr{P}_{\theta} \sim \varepsilon_{\theta},
$$


or, explicitly,

$$
-\rho c_{\mathrm{p}} \overline{u_{\mathrm{i}} \theta} \frac{\partial \Theta}{\partial x_{\mathrm{i}}} \sim-\overline{q_{\mathrm{i}}\left(\frac{\partial \theta}{\partial x_{\mathrm{i}}}\right)} .
$$

This result, in terms of Fourier's law, becomes

$$
-\overline{u_{\mathrm{i}} \theta} \frac{\partial \Theta}{\partial x_{\mathrm{i}}}=\alpha \overline{\left(\frac{\partial \theta}{\partial x_{\mathrm{i}}}\right)\left(\frac{\partial \theta}{\partial x_{\mathrm{i}}}\right)}
$$

or, in terms of the entropy production given by Eq. (39),

$$
-\rho c_{\mathrm{p}} \overline{u_{\mathrm{i}} \theta} \frac{\partial \Theta}{\partial x_{\mathrm{i}}}=-\overline{\theta^{2}} s^{\prime \prime \prime} .
$$

Equation (54) or (55) is the starting point in the development of thermal microscales of turbulence which follows.

\section{A THERMAL MICROSCALE}

On dimensional grounds, Equation (54) or (55) gives

$$
\mathscr{P}_{\theta} \sim u_{\theta} \theta \frac{\theta}{\ell} \sim \alpha \frac{\theta^{2}}{\lambda_{\theta}^{2}} \sim \varepsilon_{\theta} \sim \theta^{2} s_{\theta},
$$

where $\lambda_{\theta}$ is a thermal microscale, $\ell$ is an integral scale, and $s_{\theta}$ is a measure for thermal entropy production. Under the assumption of isotropy for length that characterizes the thickness of thermal sublayer,

$$
\lim _{\ell \rightarrow \eta} \lambda_{\theta} \rightarrow \eta_{\theta}
$$

Equation (56) yields

$$
u_{\theta} \sim \alpha \frac{\eta}{\eta_{\theta}^{2}}
$$

$\eta$ being the thickness of momentum sublayer. Assuming $\eta$ to be the smallest momentum scale, the velocity corresponding to this scale becomes

$$
u \sim \frac{v}{\eta} \sim u_{\theta}
$$

and the equality of Eqs (58) and (59) gives

$$
\frac{\eta}{\eta_{0}} \sim \operatorname{Pr}^{1 / 2}
$$

$\eta_{0}$ being the Batchelor scale. If $\eta$ were assumed rather to be the thickness of the momentum sublayer across which the velocity drops from $u$ at the core-sublayer interface to zero on boundary,

$$
u_{\theta} \sim u \frac{\eta_{\theta}}{\eta}
$$

which in terms of Eq. (59) yields

$$
u_{\theta} \sim v \frac{\eta_{\theta}}{\eta^{2}}
$$

Then, equality of Eqs (58) and (61) results in

$$
\frac{\eta}{\eta_{\theta}^{\mathrm{A}}} \sim \operatorname{Pr}^{1 / 3}
$$

$\eta_{\theta}^{\mathrm{A}}$ being another thermal microscale. In terms of the Kolmogorov scale,

$$
\eta=\left(\frac{v^{3}}{\varepsilon}\right)^{1 / 4}
$$

Equation (62) leads to the explicit form of this scale,

$$
\eta_{\theta}^{\mathrm{A}}=\left(\frac{v^{5 / 3} \alpha^{4 / 3}}{\varepsilon}\right)^{1 / 4} \text {. }
$$

In a recent study, Arpaci et al. ${ }^{19}$ develop the Kolmogorov scale for oscillating with an imposed or induced frequency $\omega$ of a Reynolds averaged turbulent flow,

$$
\eta=\frac{\left(\frac{v^{3}}{\varepsilon}\right)^{1 / 4}}{\left[1+\omega\left(\frac{v}{\varepsilon}\right)^{1 / 2}\right]^{1 / 2}}
$$

and, in terms of this scale, suggest a heat transfer correlation for pulse combustion systems, which will be discussed in Section 10. In the following section, the entropy production is related to skin friction and heat transfer in terms of these scales.

\section{HEAT TRANSFER AND ENTROPY PRODUCTION}

First, consider the usual definitions of the coefficient of heat transfer and that of friction factor in terms of $\eta_{\theta}^{A}$ and $\eta$. Thus,

$$
q \sim h \theta \sim k\left(\theta / \eta_{\theta}^{\mathrm{A}}\right)
$$

and

$$
\frac{1}{2} f \sim \frac{\tau_{w}}{\rho u^{2}} \sim \frac{\mu(u / \eta)}{\rho u^{2}} \sim \frac{v}{u \eta}
$$

which may be rearranged as

$$
h / k \sim\left(\eta_{\theta}^{\mathrm{A}}\right)^{-1}
$$

and

$$
u / v \sim\left(\frac{1}{2} f\right)^{-1} \eta^{-1}
$$

The ratio of Eqs (66) and (67) gives, under the assumption of similarity,

$$
\frac{h / k}{u / v}=\frac{1}{2} f\left(\frac{\eta}{\eta_{\theta}^{\mathrm{A}}}\right) .
$$

The left side of this result may be rearranged in terms of a characteristic length as

$$
\frac{N u}{R e}=\frac{1}{2} f\left(\frac{\eta}{\eta_{\theta}^{\mathrm{A}}}\right)
$$

or, in terms of the Stanton number,

$$
S t=N u / \operatorname{RePr},
$$

and Eq. (62), as

$$
S t \operatorname{Pr}^{2 / 3}=\frac{1}{2} f
$$

which is known to be the Colburn correlation of experimental turbulent data. 


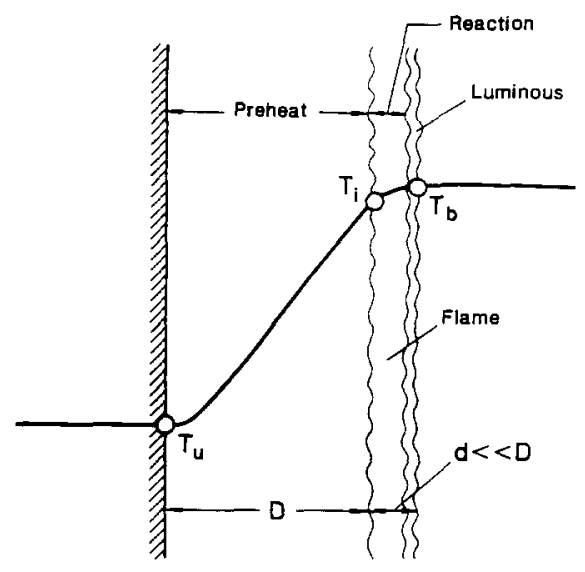

FIG. 5. Quenched laminar flame.

Now, proceed to the fundamental relation between heat transfer and entropy production. Under conditions of isotropy, Eq. (56) gives

$$
s_{\theta} \sim \frac{\alpha}{\left(\eta_{\theta}^{\mathrm{A}}\right)^{2}},
$$

or, in terms of an integral scale $\ell$,

$$
\Pi_{\mathrm{s}} \sim \frac{s_{0} \ell^{2}}{\alpha} \sim\left(\frac{\ell}{\eta_{\theta}^{\mathrm{A}}}\right)^{2}
$$

where $\Pi_{s}$ is a dimensionless number characterizing the entropy production. Also, from Eq. (66),

$$
N u \sim \frac{h \ell}{k} \sim \frac{\ell}{\eta_{\theta}^{\mathrm{A}}} .
$$

The comparison of Eqs (72) and (73) readily reveals

$$
N u \sim \Pi_{\mathrm{s}}^{1 / 2}
$$

the fundamental relation between heat transfer and entropy production. This relation holds under any (laminar, transition, turbulent) flow condition. In the proceeding sections, the fundamental concepts reviewed in the preceding sections are applied to a number of physically significant problems and technologically important systems.

\section{QUENCHED FLAME}

Consider a flat flame anchored to a porous-plug flameholder, suggested originally by Hirschfelder and co-workers ${ }^{20-22}$ for experimental studies. Such flameholders were designed and utilized earlier by Botha and Spalding, ${ }^{23}$ and Kaskan ${ }^{24}$ and recently by Ferguson and Keck. ${ }^{25,26}$ The local entropy production in such a flame, obtained from dimensional considerations on the thermal part of Eq. (39), is

$$
s^{\prime \prime \prime} \sim \frac{1}{T}\left(\frac{q^{\mathrm{K}}}{T}\right)\left(\frac{T_{\mathrm{b}}-T_{\mathrm{u}}}{D}\right),
$$

$D$ being the quench distance (the thickness of reaction zone is $d$, and $d \ll D$ ), $T_{\mathrm{u}}$ and $T_{\mathrm{b}}$ unburned and burned gas temperatures, respectively (Fig. 5).
Rearranging Eq. (75) in terms of the conduction law,

$$
q^{\mathrm{K}} \sim k \frac{T_{\mathrm{b}}-T_{\mathrm{u}}}{D},
$$

as

$$
s^{\prime \prime \prime} \sim \frac{k}{T^{2}}\left(\frac{T_{b}-T_{u}}{D}\right)^{2} .
$$

In view of the fact that most of the reaction occurs close to the highest temperature, $T_{\mathrm{b}}$ is used for the characteristic temperature in Eq. (77). Accordingly,

$$
s^{\prime \prime \prime} \sim\left(1-\frac{T_{\mathrm{u}}}{T_{\mathrm{b}}}\right)^{2} \frac{k}{D^{2}},
$$

or, in terms of a characteristic length $\ell=\alpha / S_{\mathrm{u}}^{0}, \alpha$ being the thermal diffusivity and $S_{u}^{0}$ the adiabatic laminar flame speed at the unburned gas temperature, assuming $T_{\mathrm{u}} / T_{\mathrm{b}} \ll 1$ and introducing dimensionless entropy production $\Pi_{s}$,

$$
\Pi_{\mathrm{s}}=\frac{s^{\prime \prime \prime} \ell^{2}}{k} \sim\left(P e_{D}^{0}\right)^{-2}
$$

where

$$
P e_{D}^{0}=\frac{D}{\ell}=\frac{S_{u}^{0} D}{\alpha}
$$

is the flame Peclet number. Accordingly,

$$
\Pi_{\mathrm{s}}=f\left(P e_{D}^{0}\right)
$$

where

$$
P e_{D}^{0}=f(D) \text { and } D=f\left(\theta_{\mathrm{b}}\right),
$$

and $\Pi_{s}$ depends on the flame temperature only through the Peclet number (or the dimensionless quench distance). The U-shaped nature of $D=f\left(\theta_{\mathrm{b}}\right)$ is well documented in the literature (see Ferguson and Keck; ${ }^{25,26}$ Clarke and McIntosh ${ }^{27}$ and McIntosh and Clarke $^{28}$ for the case excluding radiation, and Arpaci and Tabaczynski ${ }^{29,30}$ for the case including radiation; also, see Kooker $^{31}$ and Sohrab and $\mathrm{Law}^{32}$ for the importance of radiation on quenching process, and Lee and Tien ${ }^{33}$ for the effect of condensed fuels on this process). The Refs [25, 26, 29] and [30] follow the usual practice and evaluate the minimum quench distance from the tangency condition,

$$
\frac{\partial}{\partial \theta_{\mathrm{b}}}\left(P e_{D}^{0}\right)=0
$$

which actually corresponds to an extremum in the entropy production, that is,

$$
\frac{\partial \Pi_{\mathrm{s}}}{\partial \theta_{\mathrm{b}}} \sim-\frac{2}{\left(P e_{D}^{0}\right)^{3}} \frac{\partial}{\partial \theta_{\mathrm{b}}}\left(P e_{D}^{0}\right)=0 .
$$

This result, in view of the fact that $P e_{D}^{0} \neq 0$, is equivalent to Eq. (82) and provides the physical justification for the tangency condition. 


\section{ENTROPY PRODUCTION IN A QUENCHED FLAME}

So far we discussed the foundations of entropy production in flame quenching following some dimensional considerations. Now we proceed to a quantitative distribution of this production by referring to a thermal model for steady plane flames on a porous plug. A number of simple models have been proposed, all describing the chemistry by a single-step global Arrhenius reaction, and differing especially in the way the heat losses are taken into account. Among these, Carrier, Fendell and Bush ${ }^{34}$ use a step function heat sink in the preheat zone whereas Clarke and coworkers $^{27,28,35}$ follow the model proposed earlier by Hirschfelder and co-workers. ${ }^{20-22}$ The close agreement between these models, except for the interpretation of "cold boundary" (see, for example, Williams, ${ }^{36}$ p. 145) and the model by Matkowsky and Olagunju ${ }^{37}$ based on a modified step function which yields results different in some important respects, is well known. Also, there exists two models, proposed by Ferguson and $\mathrm{Keck}^{25,26}$ for interpretation of their experimental studies. The last two models are conveniently utilized here for a qualitative demonstration of the entropy production in flames. Following Ref. [25], we have the first order model

$$
\begin{aligned}
P e_{D}^{0} & =\frac{\rho_{\mathrm{u}} S_{\mathrm{u}}^{0} c_{\mathrm{p}} D}{k} \\
& =\left(\frac{\theta_{\mathrm{b}}-\theta_{\mathrm{u}}}{1-\theta_{\mathrm{b}}}\right) \exp \left[\frac{E}{2 \mathrm{R} T_{\mathrm{b}}^{0}}\left(\frac{1}{\theta_{\mathrm{b}}}-1\right)\right]
\end{aligned}
$$

where $\theta_{\mathrm{u}}=T_{\mathrm{u}} / T_{\mathrm{b}}^{0}$ and $\theta_{\mathrm{b}}=T_{\mathrm{b}} / T_{\mathrm{b}}^{0}$ are dimensionless temperatures, $T_{\mathrm{b}}^{0}$ being the adiabatic flame temperature, $E$ is the activation energy and $R$ is the universal gas constant. Also, following Ref. [26] we have the second order model,

$$
\begin{aligned}
P e_{D}^{0}= & \rho_{\mathrm{u}} S_{\mathrm{u}}^{0} c_{\mathrm{p}} \int_{0}^{D} \frac{\mathrm{d} x}{k}=\left[\ln \left(\frac{1-\theta_{\mathrm{u}}}{1-\theta_{\mathrm{b}}}\right)\right] \\
& \times \exp \left[\frac{E}{2 \mathrm{R} T_{\mathrm{b}}^{0}}\left(\frac{1}{\theta_{\mathrm{b}}}-1\right)\right] .
\end{aligned}
$$

Now, employing Eqs (84) and (85), we get the distribution of entropy production from Eq. (79) and plot the results in Fig. 6. On the same figure, also shown is the variation of Peclet number. The Peclet and entropy production curves labelled by I and II correspond to the first and second order models evaluated respectively from Eqs (84) and (85). The U-shape of the $P e_{D}^{0}-\theta_{\mathrm{b}}$ relation and the inverse quadratic dependence between $\Pi_{\mathrm{s}}$ and $P e_{D}^{0}$ (recall Eq. 79 ) readily explain the maximum as well as the relatively squeezed shape of the $\Pi_{s}-\theta_{b}$ relation.

For the spatial distribution of entropy production between the burner and flame, consider the temperature distribution from Ref. [26]

$$
\frac{T-T_{\mathrm{u}}}{T_{\mathrm{b}}^{0}-T_{\mathrm{u}}}=\left(\frac{T_{\mathrm{b}}-T_{\mathrm{u}}}{T_{\mathrm{b}}^{0}-T_{\mathrm{u}}}\right)\left(\frac{\mathrm{e}^{\xi}-1}{\mathrm{e}^{P e_{D}}-1}\right)
$$

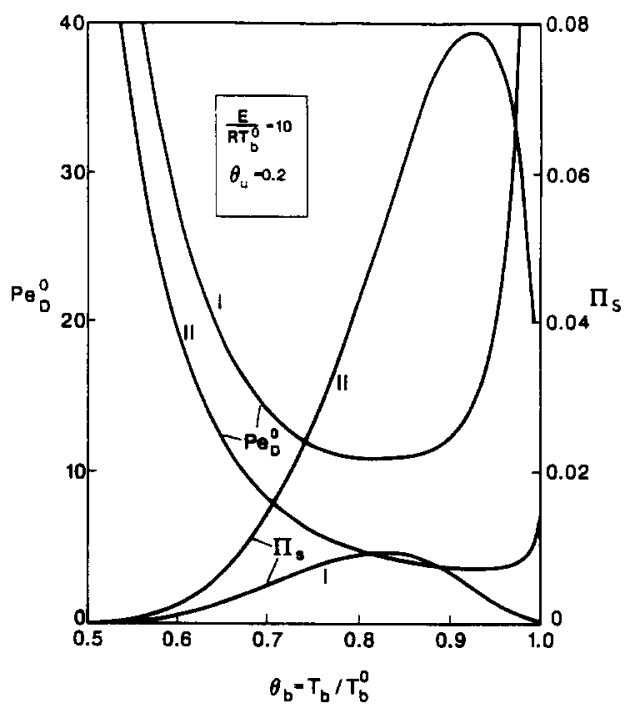

Fig. 6. First and second order $P e_{D}^{0}$ and $\Pi_{\mathrm{s}}$ versus $\theta_{\mathrm{b}}=$ $T_{\mathrm{b}} / T_{\mathrm{b}}^{0}$.

where

$$
\xi=\rho_{\mathrm{u}} S_{\mathrm{u}} c_{\mathrm{p}} \int_{0}^{x} \frac{\mathrm{d} x^{\prime}}{k} .
$$

Rearrange the temperature distribution in terms of

$$
\theta=\frac{T}{T_{\mathrm{b}}^{0}} \text { and } P e_{D}=\ln \left(\frac{1-\theta_{\mathrm{u}}}{1-\theta_{\mathrm{b}}}\right)
$$

to obtain

$$
\theta(\xi)=\theta_{\mathrm{u}}+\theta_{\mathrm{b}}-1+\left(1-\theta_{\mathrm{b}}\right) \mathrm{e}^{\xi}
$$

and

$$
\frac{\mathrm{d} \theta}{\mathrm{d} \xi}=\left(1-\theta_{\mathrm{b}}\right) \mathrm{e}^{\xi}
$$

Now, for the thermal part of entropy production, Eq. (39) gives,

$$
\Pi_{\mathrm{s}}=\frac{s^{\prime \prime \prime} \ell^{2}}{k}=\frac{\ell^{2}}{T^{2}}\left(\frac{\mathrm{d} T}{\mathrm{~d} x}\right)^{2}
$$

which may be rearranged as

$$
\Pi_{\mathrm{s}}=\frac{1}{\theta_{2}}\left[\frac{\mathrm{d} \theta}{\mathrm{d}(x / \ell)}\right]^{2}
$$

In terms of $\ell=\alpha / S_{\mathrm{u}}^{0}$ and for a constant $k$,

$$
\frac{x}{\ell}=\frac{\rho_{\mathrm{u}} c_{\mathrm{p}} S_{\mathrm{u}}^{0} x}{k}=\frac{S_{\mathrm{u}} x / \alpha}{S_{\mathrm{u}} / S_{\mathrm{u}}^{0}},
$$

or,

$$
\frac{x}{\ell}=\frac{\xi}{S_{\mathrm{u}} / S_{\mathrm{u}}^{0}} .
$$

Now, in terms of $\xi$, Eq. (90) becomes

$$
\Pi_{\mathrm{s}}=\frac{1}{\theta^{2}}\left(\frac{\mathrm{d} \theta}{\mathrm{d} \xi}\right)^{2}\left(\frac{S_{\mathrm{u}}}{S_{\mathrm{u}}^{0}}\right)^{2}
$$

which, with the experimental correlation

$$
\frac{S_{\mathrm{u}}}{S_{\mathrm{u}}^{0}}=\exp \left[-\frac{E}{2 \mathrm{R} T_{\mathrm{b}}^{0}}\left(\frac{1}{\theta_{\mathrm{b}}}-1\right)\right]
$$




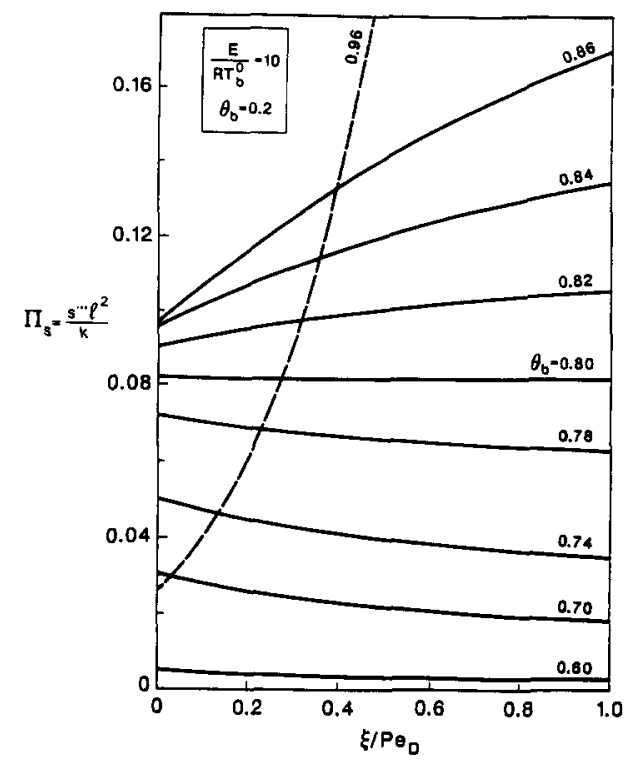

FIG. 7. Spatial distribution of entropy production.

of Kaskan, ${ }^{24}$ yields

$$
\Pi_{\mathrm{s}}=\frac{1}{\theta^{2}}\left(\frac{\mathrm{d} \theta}{\mathrm{d} \xi}\right)^{2} \exp \left[-\frac{E}{\mathrm{R} T_{\mathrm{b}}^{0}}\left(\frac{1}{\theta_{\mathrm{b}}}-1\right)\right] .
$$

Finally, referring to Eqs (87) and (88) for $\theta$ and $\mathrm{d} \theta / \mathrm{d} \xi$, Eq. (94) may be rearranged as

$$
\begin{aligned}
\Pi_{\mathrm{s}}= & {\left[\frac{\left(1-\theta_{\mathrm{b}}\right) \mathrm{e}^{\xi}}{\theta_{\mathrm{u}}+\theta_{\mathrm{b}}-1+\left(1-\theta_{\mathrm{b}}\right) \mathrm{e}^{\xi}}\right]^{2} } \\
& \times \exp \left[-\frac{E}{\mathrm{R} T_{\mathrm{b}}^{0}}\left(\frac{1}{\theta_{\mathrm{b}}}-1\right)\right] .
\end{aligned}
$$

Note that for

$$
\theta_{\mathrm{u}}+\theta_{\mathrm{b}}=1
$$

Eq. (95) reduces to

$$
\Pi_{\mathrm{s}}=\exp \left[-\frac{E}{\mathrm{R} T_{\mathrm{b}}^{0}}\left(\frac{1}{\theta_{\mathrm{b}}}-1\right)\right]
$$

which, for a fixed $E / \mathbf{R} T_{\mathrm{b}}^{0}$ and $\theta_{\mathrm{b}}$, becomes constant. Figure 7 shows $\Pi_{\mathrm{s}}$ versus $\xi / P e_{D}$ for $\theta_{u}=0.2$ and $E / \mathrm{R} T_{\mathrm{b}}^{0}=10$. The entropy production between the flame and burner appears to be almost uniform. Since the quench distance is rather small, say $0.5-1 \mathrm{~mm},{ }^{26}$ this result is not surprising. For $\theta_{\mathrm{b}}=1-\theta_{\mathrm{u}}$, this production becomes exactly uniform. However, for $\theta_{b}>1-\theta_{u}$, the behaviour of production drastically changes as demonstrated in Fig. 7 with $\theta_{b}=0.96$. The uniformity of as well as the drastic change in entropy production do not accept a ready interpretation. It may be more of a property of the model rather than the reality. The quantitative difference between the model and experimental results (see Fig. 6 of Ref. [26]) for $\theta_{b}>1-\theta_{u}$ add some credence to this statement.

Law and co-workers ${ }^{38,39}$ have recently disagreed with the Keck quench models by stating that a flame

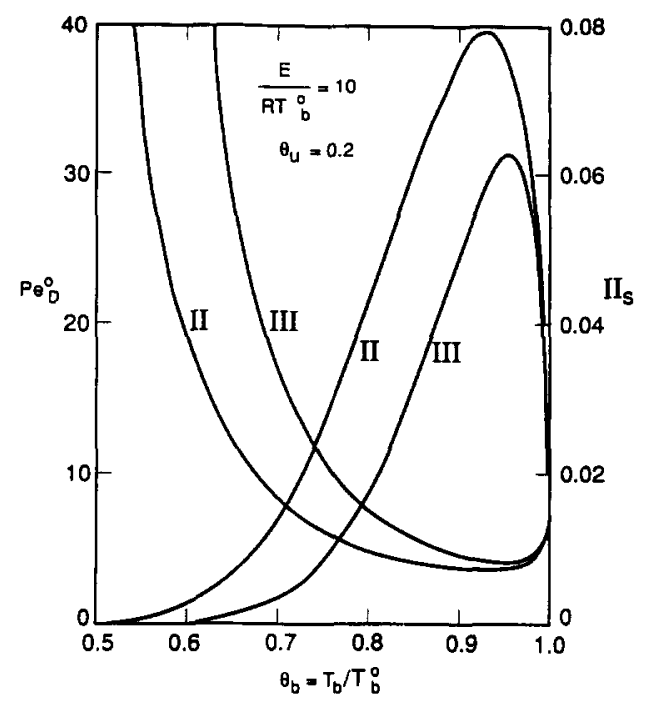

Fig. 8. Ferguson and $\mathrm{Keck}^{26}$ (II) and McIntosh and Clarke ${ }^{28}$ (III) models for $P e_{D}^{0}$ and $\Pi_{s}$.

can always be stabilized over a burner by adjusting the stand-off distance and thereby the heat-loss rate; the flame may be blown off but not quenched by a discharge rate exceeding the laminar flame speed. However, the objective of the review is not to side with one of the views but is rather to demonstrate the entropy production (and entropic efficiency) of fiames in terms of a simple model. Among the flame models existing in the literature, the foregoing Ferguson and Keck models were employed merely because of their simplicity. A third and somewhat more involved model, based on studies of Clarke and co-workers, ${ }^{27,28,35}$ and resting on the flame speed

$$
\frac{S_{\mathrm{u}}}{S_{\mathrm{u}}^{0}}=\left(\frac{T_{\mathrm{b}}}{T_{\mathrm{b}}^{0}}\right)^{2} \exp \left[-\frac{E}{2 \mathrm{R} T_{\mathrm{b}}^{0}}\left(\frac{1}{\theta_{\mathrm{b}}}-1\right)\right]
$$

readily yields

$$
P e_{D}^{0}=\frac{1}{\theta_{\mathrm{b}}^{2}} \ln \left(\frac{1-\theta_{\mathrm{u}}}{1-\theta_{\mathrm{b}}}\right) \exp \left[\frac{E}{2 \mathrm{R} T_{\mathrm{b}}^{0}}\left(\frac{1}{\theta_{\mathrm{b}}}-1\right)\right],
$$

or,

$$
\left(P e_{D}^{0}\right)_{\mathrm{III}}=\theta_{\mathrm{b}}^{-2}\left(P e_{D}^{0}\right)_{\mathrm{II}}
$$

and

$$
\left(\Pi_{\mathrm{s}}\right)_{\mathrm{III}}=\theta_{\mathrm{b}}^{4}\left(\Pi_{\mathrm{s}}\right)_{\mathrm{II}}
$$

where subscripts II and III respectively refer to the second order Ferguson and Keck model and the Clarke model. A numerical comparison between these models shows that, in spite of its relative complexity, the Clarke model relative to the Ferguson and Keck models appear to provide a limited improvement in approximating real flames (Fig. 8).

The range of $\theta_{\mathrm{u}}$ is $0.12-0.25$ and the range of $E / R T_{\mathrm{b}}^{0}$ for ordinary hydrocarbon fuels (say, methane, propane and octane) reacting with air is

$$
E / \mathrm{R} T_{\mathrm{b}}^{0}=5-15 \text {. }
$$




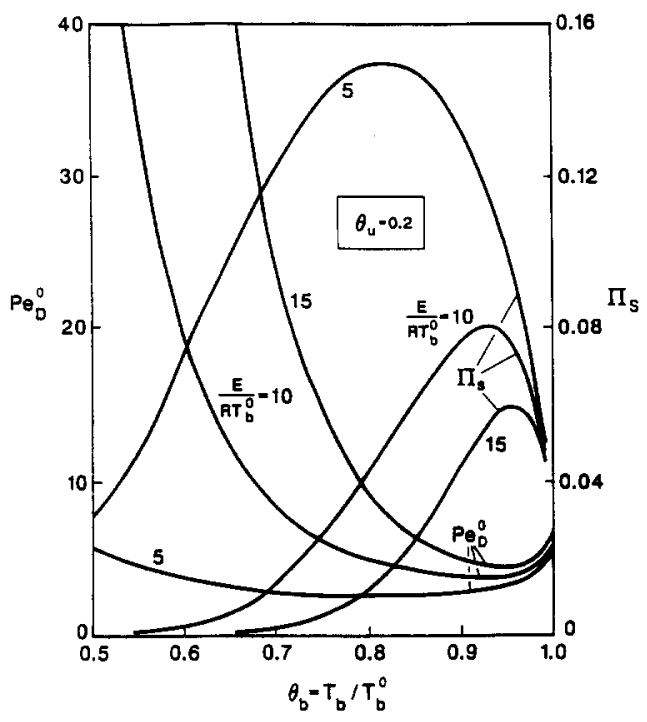

FlG. 9. Effect of activation energy on $P e_{D}^{0}$ and $\Pi_{s}$.

Figure 9 shows the variation of $P e_{D}^{0}$ and $\Pi_{s}$ based on the second order Ferguson and Keck model. Here, $E / \mathrm{R} T_{\mathrm{b}}^{0}=10$ qualitatively represents (for the stoichiometric mixture with air) a lower bound for propane and an upper bound for ( $n$-Octane), and $E / \mathbf{R} T_{\mathrm{b}}^{0}=15$ an upper bound for methane. Actually, there remains a considerable disagreement in the literature on the activation energy of methane (see, for example, the tables in Kanury, ${ }^{40}$ p. 109; Mullins, ${ }^{41}$ pp. 201-220; and $\mathrm{Kaskan}^{24}$ ). This disagreement is a result of the complexities associated with $\mathrm{CH}_{4}$ oxidation (Westbrook and Dryer ${ }^{42}$ and Glassman, ${ }^{43}$ p. 81 ). Here, we utilized, somewhat arbitrarily, the values suggested by Kaskan. $^{24}$

It has recently been shown by Law and coworkers $^{38,39,44-47}$ that the accurate determination of the laminar flame speed requires the consideration of a more realistic kinetic schemes than the one used in this review. Among these, the models by Kee et al. and Warnat ${ }^{48}$ both agree with the experimental data of Egolfopoulos $e t$ al. ${ }^{39}$ over some concentration and pressure ranges. Yet, there remains small but important differences on some of the predictions of these models. Further code developments are needed to resolve these differences. Therefore, any study based on these models has to be delayed until the resolution of these differences.

\section{ENTROPY PRODUCTION IN A BOUNDARY LAYER}

Consider a radiation affected forced convection boundary layer over a horizontal flat plate. For heat transfer studies, rather than velocity profiles, a good approximation of these profiles near boundaries is convenient. This approach, in the absence of radiation, is well known and has been studied extensively (see Curle ${ }^{49}$ for an early reference, and Arpaci and Larsen $^{2}$ for a later reference). Also, the extension of the approach to the limiting cases of $P r \ll 1$ and $\operatorname{Pr} \gg 1$ are discussed in Arpaci and Larsen. ${ }^{2}$ Since the case of $\operatorname{Pr} \ll 1$ is for opaque fluids and has no application to radiation-affected problems, and the case of $\operatorname{Pr} \gg 1$ is known to approximate for all fluids with $\operatorname{Pr} \geqslant 1$, only the latter case is considered below.

Replacing the longitudinal velocity by its tangent on the wall and using this velocity in the conservation of mass to determine the transverse velocity, and including the radiation effect, the thermal energy balance gives

$$
\begin{gathered}
\rho c_{\mathrm{p}}\left[y\left(\frac{\tau_{\mathrm{w}}}{\mu}\right) \frac{\partial T}{\partial x}-\frac{1}{2} y^{2} \frac{\mathrm{d}}{\mathrm{d} x}\left(\frac{\tau_{\mathrm{w}}}{\mu}\right) \frac{\partial T}{\partial y}\right] \\
=k \frac{\partial^{2} T}{\partial y^{2}}-\frac{\partial q_{\mathrm{y}}^{\mathrm{R}}}{\partial y}
\end{gathered}
$$

subject to (Lord and Arpaci ${ }^{50}$ )

$$
\frac{\partial q_{\mathrm{y}}^{\mathrm{R}}}{\partial y}=4 \kappa_{\mathrm{p}}\left[\left(E_{\mathrm{b}}-E_{\mathrm{b} \infty}\right)-\frac{\varepsilon_{\mathrm{w}}}{2}\left(E_{\mathrm{bw}}-E_{\mathrm{b} \infty}\right) E_{2}(\tau)\right] \text {, }
$$

where $\tau_{w}$ denotes the wall shear stress, $\kappa_{\mathrm{p}}$ the Planck mean absorption coefficient, $E_{\mathrm{b}}$ the emissive power, $\varepsilon_{\mathrm{w}}$ the wall emissivity, $E_{2}$ the second exponential integral, and $\tau$ the optical thickness. The boundary conditions to be satisfied are

$$
T(0, y)=T_{\infty}, T(x, 0)=T_{w}, T(x, \infty)=T_{\infty} .
$$

A similarity variable including both conduction and radiation is not feasible because of intrinsic lack of similarity between conduction and radiation. However, the effect of thin-gas radiation on conduction is small. This fact suggests the use of the similarity variable for conduction by which the radiation effect can be treated locally similar.

Introducing $\eta=y / g(x)$ (see, for example, Arpaci and Larsen $^{2}$ ), into Eq. (102) leads to the equation satisfied by $g(x)$,

$$
\left(\frac{\tau_{w}}{\mu}\right) \frac{\mathrm{d} g^{3}}{\mathrm{~d} x}+\frac{3}{2} g^{3} \frac{\mathrm{d}}{\mathrm{d} x}\left(\frac{\tau_{w}}{\mu}\right)=\alpha
$$

which readily gives

$$
\begin{aligned}
& g(x)=\frac{\left[\alpha \int_{0}^{x}\left(\tau_{w} / \mu\right)^{1 / 2} \mathrm{~d} x\right]^{1 / 3}}{\left(\tau_{w} / \mu\right)^{1 / 2}} \\
& \text { and } \eta=\frac{\left(\tau_{w} / \mu\right)^{1 / 2} y}{\left[\alpha \int_{0}^{x}\left(\tau_{w} / \mu\right)^{1 / 2} \mathrm{~d} x\right]^{1 / 3}} .
\end{aligned}
$$

In terms of Eq. (105) and the approximation $E_{2} \simeq$ $\exp (-\sqrt{3} \tau)$, Eqs (102) and (103) are combined to give

$$
\frac{\mathrm{d}^{2} \theta}{\mathrm{d} \eta^{2}}+\frac{1}{3} \eta^{2} \frac{\mathrm{d} \theta}{\mathrm{d} \eta}=\chi P \gamma^{2} x\left(\Theta^{4}-\frac{\varepsilon_{\mathrm{w}}}{2} \mathrm{e}^{-\gamma x^{1 / 2 \eta}}\right)
$$




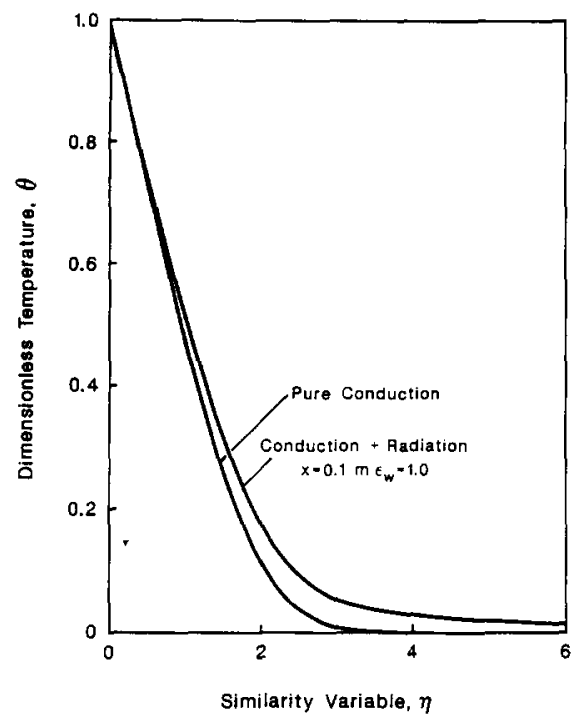

FIG. 10. Dimensionless temperature versus similarity variable.

subject to $\theta(0)=1$ and $\theta(\infty)=0$. Here, $\chi=\left(\kappa_{\mathrm{p}} /\right.$ $\left.\kappa_{\mathrm{R}}\right)^{1 / 2}$ is the weighted nongrayness, $\kappa_{\mathrm{R}}$ the Rosseland mean absorption coefficient and

$$
\begin{aligned}
& \theta=\frac{T-T_{\infty}}{T_{\mathrm{w}}-T_{\infty}}, \Theta^{4}=\frac{T^{4}-T_{\infty}^{4}}{T_{\mathrm{w}}^{4}-T_{\infty}^{4}}, \gamma=\sqrt{3} \kappa_{\mathrm{M}} G \\
& g=G x^{1 / 2}, G=\left[\frac{4 \alpha / 3}{0.332 U_{\infty}\left(U_{\infty} / v\right)^{1 / 2}}\right]^{1 / 3} \quad(107) \\
& P=\frac{4}{3} \frac{\sigma\left(T_{\mathrm{w}}^{4}-T_{\infty}^{4}\right)}{k\left(T_{\mathrm{w}}-T_{\infty}\right) \kappa_{\mathrm{M}}} \simeq \frac{\text { Emission }}{\text { Conduction over } \kappa_{\mathrm{M}}^{-1}}
\end{aligned}
$$

$\kappa_{\mathrm{M}}=\left(\kappa_{\mathrm{P}} \kappa_{\mathrm{R}}\right)^{1 / 2}$ being the mean absorption coefficient. As $P \rightarrow 0$, the effect of radiation diminishes and Eq. (106) reduces to the case of pure conduction, as expected.

Equation (106) has been solved by Selamet and Arpaci $^{12}$ who use the finite difference code PASVA3 developed by Lentini and Pereyra ${ }^{51}$ as well as the single step code DVERK based on a fifth and sixth order Runge Kutta-Verner approximation developed by Hull et al. ${ }^{52}$ The results obtained separtely from PASVA3 and DVERK have been found to agree to five decimals. Figure 10 shows the variation of $\theta$ against $\eta$, for pure conduction which can be obtained by letting the right hand side of Eq. (106) equal to zero, and combination of conduction and radiation as expressed by Eq. (106).

In terms of $\eta$ and $\theta$, the conductive constitution becomes

$$
q_{y}^{\mathrm{K}}=-\frac{k}{\mathrm{~g}} \frac{\mathrm{d} \theta}{\mathrm{d} \eta}\left(T_{\mathrm{w}}-T_{\infty}\right)
$$

where $\eta$ and $g$ are defined by Eqs (105) and (107), respectively. Inserting $T$, the thin-gas radiative heat flux, and the conductive heat flux expressed by Eq. (108), into Eq. (39), the volumetric local entropy

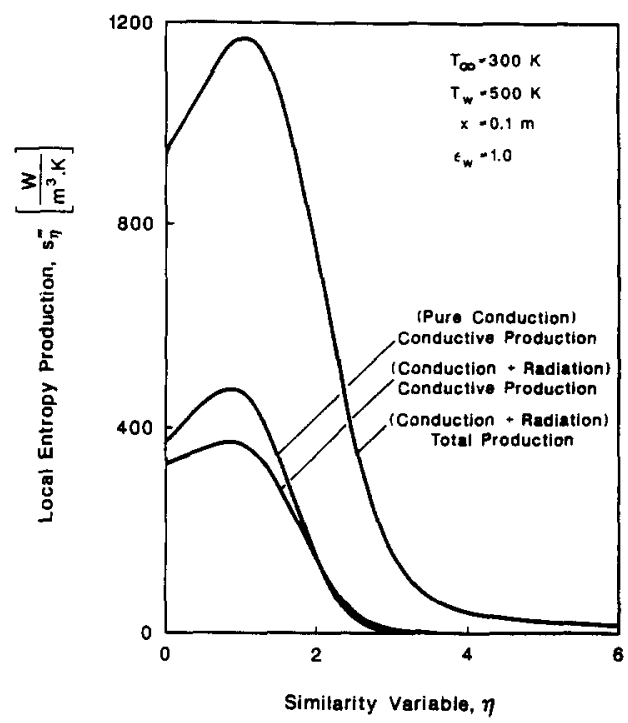

Fig. 11. Rate of local entropy production versus similarity variable.

production has been shown to be

$$
\begin{aligned}
s_{\eta}^{\prime \prime \prime}= & \frac{\left(-\frac{\mathrm{d} \theta}{\mathrm{d} \eta}\right)}{g\left(\theta+\frac{T_{\infty}}{T_{\mathrm{w}}-T_{\infty}}\right)^{2}} \\
& \times\left[-\frac{k}{\mathrm{~g} \theta} \frac{\mathrm{d} \theta}{\mathrm{d} \eta}+\varepsilon_{\mathrm{w}} \sigma\left(T_{\mathrm{w}}+T_{\infty}\right)\left(T_{\mathrm{w}}^{2}+T_{\infty}^{2}\right)\right] .
\end{aligned}
$$

For illustrative purposes, assuming a wall temperature of $T_{\mathrm{w}}=500 \mathrm{~K}$, Fig. 11 depicts the variation of $s_{\eta}^{\prime \prime \prime}$ against $\eta$, for pure conduction, conductive, and total (conductive + radiative) components in combined conduction and radiation problems.

For the heat transfer in boundary layers, consider the total heat flux on boundaries,

$$
q_{w}=q_{w}^{\mathrm{C}}+q_{w}^{\mathrm{R}} \text {, }
$$

$q_{w}^{C}$ being available from a usual boundary approach and $q_{\mathrm{w}}^{\mathrm{R}}$ being the spectral average of the monochromatic wall heat flux to be evaluated next. From Özişik, ${ }^{53}$ Siegel and Howell, ${ }^{54}$ or Sparrow and Cess, ${ }^{55}$

$$
q_{w}^{\mathrm{R}}=\varepsilon_{\mathrm{w}}\left[E_{\mathrm{bw}}-2 \int_{0}^{\infty} E_{\mathrm{b}} E_{2}\left(\tau^{\prime}\right) \mathrm{d} \tau^{\prime}\right] .
$$

After splitting the interval into two domains as $\left[0, \tau_{\Delta}\right]$ and $\left[\tau_{\Delta}, \infty\right], \tau_{\Delta}$ denoting the thickness of the conduction boundary layer, the integration of Eq. (111) yields

$$
q_{w}^{\mathbf{R}} \simeq-2 \varepsilon_{w} \int_{0}^{\tau} \frac{\mathrm{d} E_{\mathrm{b}}}{\mathrm{d} \tau^{\prime}} E_{3}\left(\tau^{\prime}\right) \mathrm{d} \tau^{\prime} .
$$

A third order polynomial in $\tau$ for $E_{\mathrm{b}}$ satisfying the apparent conditions,

$$
E_{\mathrm{b}}(0)=E_{\mathrm{bw}}, E_{\mathrm{b}}\left(\tau_{\Delta}\right) \simeq E_{\mathrm{b} \infty} \text { and } \mathrm{d} E_{\mathrm{b}}\left(\tau_{\Delta}\right) / \mathrm{d} \tau \simeq 0 \text {, }
$$


and the limit of weak radiation,

$$
\mathrm{d}^{2} E_{\mathrm{b}}(0) / \mathrm{d} \tau^{2} \rightarrow 0,
$$

yields

$$
\frac{E_{\mathrm{b}}-E_{\mathrm{bw}}}{E_{\mathrm{bw}}-E_{\mathrm{b} \infty}}=\frac{1}{2}\left(\frac{\tau}{\tau_{\Delta}}\right)^{3}-\frac{3}{2}\left(\frac{\tau}{\tau_{\Delta}}\right) .
$$

In terms of Eq. (115), the wall heat flux from Eq. (112) yields

$$
q_{\mathrm{w}}^{\mathrm{R}}=\varepsilon_{\mathrm{w}}\left(E_{\mathrm{bw}}-E_{\mathrm{b} \infty}\right)\left(1-\frac{3}{4} \tau_{\Delta}\right) .
$$

This relation apparently excludes the effect of conduction. To include this effect, reconsider the conditions given by Eq. (113), and, in place of Eq. (114), now utilize the wall balance of the thermal energy,

$$
\left.k \frac{\mathrm{d}^{2} T}{\mathrm{~d} y^{2}}\right|_{\mathrm{w}}=\left.\frac{\mathrm{d} q_{y}^{\mathrm{R}}}{\mathrm{d} y}\right|_{\mathrm{w}}
$$

which in terms of Eq. (103) may be rearranged to give $\left.k \frac{\mathrm{d}^{2} T}{\mathrm{~d} y^{2}}\right|_{\mathrm{w}}=4 \kappa_{\mathrm{p}}\left(1-\frac{\varepsilon_{\mathrm{w}}}{2}\right)\left(E_{\mathrm{bw}}-E_{\mathrm{b} \infty}\right)$.

Also, from the (linearized) Stefan-Boltzmann law

$$
\frac{\mathrm{d}^{2} E_{\mathrm{b}}}{\mathrm{d} y^{2}}=4 \sigma T_{\mathrm{M}}^{3} \frac{\mathrm{d}^{2} T}{\mathrm{~d} y^{2}},
$$

where $T_{\mathrm{M}}=\left[\left(\varepsilon_{\mathrm{w}} T_{\mathrm{w}}^{4}+T_{\infty}^{4}\right) /\left(\varepsilon_{\mathrm{w}}+1\right)\right]^{1 / 4}$. The elimination of thermal curvature between Eqs (118) and (119) gives

$$
\left.\frac{\mathrm{d}^{2} E_{\mathrm{b}}}{\mathrm{d} \tau^{2}}\right|_{\mathrm{w}}=12 \chi \mathscr{P}\left(1-\frac{\varepsilon_{\mathrm{w}}}{2}\right)\left(E_{\mathrm{bw}}-E_{\mathrm{b} \infty}\right),(12
$$

where $\mathscr{P}=4 \sigma T_{\mathrm{M}}^{4} / 3 k T_{\mathrm{M}} \kappa_{\mathrm{M}}$. Then, the polynomial approximation subject to Eqs (113) and (120) yields

$$
\begin{aligned}
\frac{E_{\mathrm{b}}-E_{\mathrm{bw}}}{E_{\mathrm{bw}}-E_{\mathrm{b} \infty}}= & \frac{1}{2}\left[-\left(3+\frac{1}{2} \mathscr{P}_{0}\right) \frac{\tau}{\tau_{\Delta}}+\mathscr{P}_{0}\left(\frac{\tau}{\tau_{\Delta}}\right)^{2}\right. \\
& \left.+\left(1-\frac{1}{2} \mathscr{P}_{0}\right)\left(\frac{\tau}{\tau_{\Delta}}\right)^{3}\right]
\end{aligned}
$$

where $\mathscr{P}_{0}=12 \chi \mathscr{P}\left(1-\varepsilon_{\mathrm{w}} / 2\right) \tau_{\Delta}^{2}$. In terms of Eq. (121), Eq. (112) results in

$$
\begin{gathered}
q_{\mathrm{w}}^{\mathrm{R}}=\varepsilon_{\mathrm{w}}\left(E_{\mathrm{bw}}-E_{\mathrm{b} \infty}\right) \\
\times\left\{1-\tau_{\Delta}\left[\frac{3}{4}-\left(1-\frac{\varepsilon_{\mathrm{w}}}{2}\right) \tau_{\Delta}^{2} \chi \mathscr{P}\right]\right\}
\end{gathered}
$$

which shows the explicit effect of conduction on the radiative heat flux. However, for the thin-gas radiation, $\tau_{\Delta} \mathscr{P} \sim 1, \tau_{\Delta} \ll 1$, and, to first order, the explicit effect of conduction on the radiation flux is negligible, and Eq. (122) reduces to Eq. (116) which is the upper limit of the radiative flux obtained from pure radiative considerations. Now, in terms of this flux, the total heat transfer becomes

$q_{\mathrm{w}}=-\left.k \frac{\partial T}{\partial y}\right|_{\mathrm{w}}+\varepsilon_{\mathrm{w}}\left(E_{\mathrm{bw}}-E_{\mathrm{b} \infty}\right)\left(1-\frac{3}{4} \tau_{\Delta}\right)$ where, after neglecting the effect of thin-gas radiation on the thermal boundary layer, $\tau_{\Delta}=\kappa_{\mathrm{M}} \Delta=\kappa_{\mathrm{M}} \delta /$ $\operatorname{Pr}^{1 / 3}$. From approximate studies on viscous boundary layers, $\delta \simeq 5.0 x / \operatorname{Re}_{\mathrm{x}}^{3 / 2}$, and $\tau_{\Delta}=5.0 \tau_{\mathrm{x}} / \operatorname{Re}_{\mathrm{x}}^{1 / 2} \operatorname{Pr}^{1 / 3}$. Also, from thermal boundary layer studies,

$$
N u_{\mathrm{x}}=0.629\left(-\mathrm{d} \theta /\left.\mathrm{d} \eta\right|_{\mathrm{w}}\right) \operatorname{Re}_{\mathrm{x}}^{1 / 2} \operatorname{Pr}^{1 / 3},
$$

which, for the pure conduction case

$$
\left(-\mathrm{d} \theta /\left.\mathrm{d} \eta\right|_{w}\right)^{\mathrm{K}}=0.538
$$

gives

$N u_{\mathrm{x}}^{\mathrm{K}}=0.339 \operatorname{Re}_{\mathrm{x}}^{1 / 2} \operatorname{Pr}^{1 / 3}$ and $\tau_{\Delta} \simeq \frac{5}{3} \tau_{\mathrm{x}} / N u_{\mathrm{x}}^{\mathrm{K}}$.

Thus

$$
\begin{gathered}
\frac{N u_{\mathrm{x}}}{N u_{\mathrm{x}}^{\mathrm{K}}}=\frac{\left(-\mathrm{d} \theta /\left.\mathrm{d} y\right|_{\mathrm{w}}\right)}{\left(-\mathrm{d} \theta /\left.\mathrm{d} y\right|_{\mathrm{w}}\right)^{\mathrm{K}}} \\
+\frac{3}{4} \varepsilon_{\mathrm{w}} P\left(\frac{\tau_{\mathrm{x}}}{N u_{\mathrm{x}}^{\mathrm{K}}}\right)\left(1-\frac{5}{4} \frac{\tau_{\mathrm{x}}}{N u_{\mathrm{x}}^{\mathrm{K}}}\right)
\end{gathered}
$$

and the local thermal entropy production on the wall is

$$
s_{\mathrm{x}}^{\prime \prime \prime}=-\left.\frac{1}{T_{\mathrm{w}}^{2}}\left(q_{\mathrm{w}}^{\mathrm{K}}+q_{\mathrm{w}}^{\mathrm{R}}\right)\left(\frac{\partial T}{\partial y}\right)\right|_{\mathrm{w}} .
$$

Introducing a wall local entropy production number, $\Pi_{\mathrm{x}}=s_{\mathrm{x}}^{\prime \prime \prime} x^{2} / k$, Eq. (126) can be rearranged into

$$
\Pi_{\mathrm{x}}=\left(1-\frac{T_{\infty}}{T_{\mathrm{w}}}\right)^{2}\left(1+\frac{q_{\mathrm{w}}^{\mathrm{R}}}{q_{\mathrm{w}}^{\mathrm{K}}}\right)\left[\frac{\left.(\partial T / \partial y)\right|_{\mathrm{w}}}{\left(T_{\mathrm{w}}-T_{\infty}\right) / x}\right]^{2}
$$

With the definition of local Nusselt number

$$
N u_{\mathrm{x}}=\frac{q_{\mathrm{x}}^{\mathrm{C}}}{q_{\mathrm{x}}^{\mathrm{K}}}=\frac{q_{\mathrm{w}}^{\mathrm{K}}}{q_{\mathrm{x}}^{\mathrm{K}}}=\frac{\left.(\partial T / \partial y)\right|_{\mathrm{w}}}{\left(T_{\mathrm{w}}-T_{\infty}\right) / x}
$$

Eq. (127) is expressed as

$$
\Pi_{\mathrm{x}}=\left(1-\frac{T_{\infty}}{T_{\mathrm{w}}}\right)^{2}\left(1+\frac{q_{\mathrm{w}}^{\mathrm{R}}}{q_{\mathrm{w}}^{\mathrm{K}}}\right) N u_{\mathrm{x}}^{2} .
$$

Next and finally, the fundamental concepts reviewed in the first six sections are applied to pulse combustion systems.

\section{PULSE COMBUSTION SYSTEMS}

Pulse combustion heating systems have many advantages over conventional burners, such as thermal efficiencies of $95 \%$ or more, low pollutant $\left(\mathrm{NO}_{x}\right.$ and $\mathrm{CO}$ ) emissions, self aspiration, and a high rate of convective heat transfer in the tailpipe. The reason for high rates of heat transfer is the large flow oscillations caused by the acoustic resonance of the combustor. However, until recently, there has been considerable confusion in the literature over the effect of flow oscillations on heat transfer rates in turbulent flows. Heat transfer rates in pulse combustor tailpipes have been found to vary from $70 \%$ or less, ${ }^{56}$ to $240 \%$ or greater, ${ }^{57}$ than those of steady flow at the same 
mean Reynolds number. Other oscillating flows have shown decreases ${ }^{58}$ in the heat transfer coefficient of up to $20 \%$ and increases ${ }^{59}$ of up to a factor of 5 over steady flow conditions. Part of these inconsistencies may be explained by the greatly different flow conditions of the studies. Also, previous studies lacked systematic variation of the important flow parameters, and many studies were conducted at frequencies much lower than the 45 to $200 \mathrm{~Hz}$ range, typical of pulse combustors. The effect of flow oscillations on pulse combustor tailpipe heat transfer has recently been clarified by the experimental study of Dec and Keller ${ }^{60}$ and that of Keller et al. ${ }^{6,, 62}$ In this section, the experimental results of Dec and Keller ${ }^{60}$ are correlated by one of the foregoing heat transfer models.

Previous modeling of oscillating flow heat transfer has been based on quasi-steady assumptions, which are valid only in flows with oscillation frequencies lower than those typical of pulse combustors, and results in a heat transfer correlation which is independent of frequency. ${ }^{63,64}$ That is, at any point in the cycle the flow is assumed to behave as if it were steady at the instantaneous velocity. This assumption is valid only for flows with low frequency oscillations, since it requires that the flow become steady within a time much less than the cycle time. Although the frequency range of the oscillations in the pulse combustor tailpipe are beyond the quasi-steady limit, it is the only theory available, and therefore widely used in the literature. The first known use of this approach was by Martinelli. ${ }^{65}$ Since then it has been used by several other researchers. ${ }^{57,58,64,66}$ For example, Hanby ${ }^{57}$ suggests

$$
\begin{gathered}
N u=0.023 \operatorname{Pr}^{1 / 3} \overline{\operatorname{Re}}^{0.8} \\
\times \int_{0}^{1}\left(\left|1+\frac{U_{0}}{U} \cos (2 \pi \tau)\right|\right)^{0.8} \mathrm{~d} \tau
\end{gathered}
$$

which is a quasi-steady adaptation of the Colburn correlation for turbulent heat transfer. Here $\mathrm{Nu}, \mathrm{Pr}$, and $\overline{R e}$ are the Nusselt number, Prandtl number and Reynolds number based on the mean velocity respectively, $\tau$ is the time normalized by the time for a complete cycle, and the oscillating velocity is assumed to be sinusoidal (an assumption verified by the velocity measurements ${ }^{67}$ ). Equation (130) provides a Nusselt number correlation, independent of frequency.

The heat transfer data of Dec and Keller, which was obtained over a range of typical pulse combustor frequencies ( 54 to $101 \mathrm{~Hz}$ ), demonstrates a strong frequency dependence that cannot be explained by a quasi-steady model. Figure 12 shows Nusselt numbers for several frequencies at the same $p_{\text {RMS }}$, approximately $7.7 \mathrm{kPa}$, and a linear least-squares fit to the axial injection data (dashed line). Examination of the linear fit also shows that the Nusselt number increase with frequency only occurs for frequencies above some minimum value. This fact, and the simultaneous near linear dependence of the Nusselt number on both frequency and $p_{\mathrm{RMS}}$, lead Dec and Keller ${ }^{60}$ to

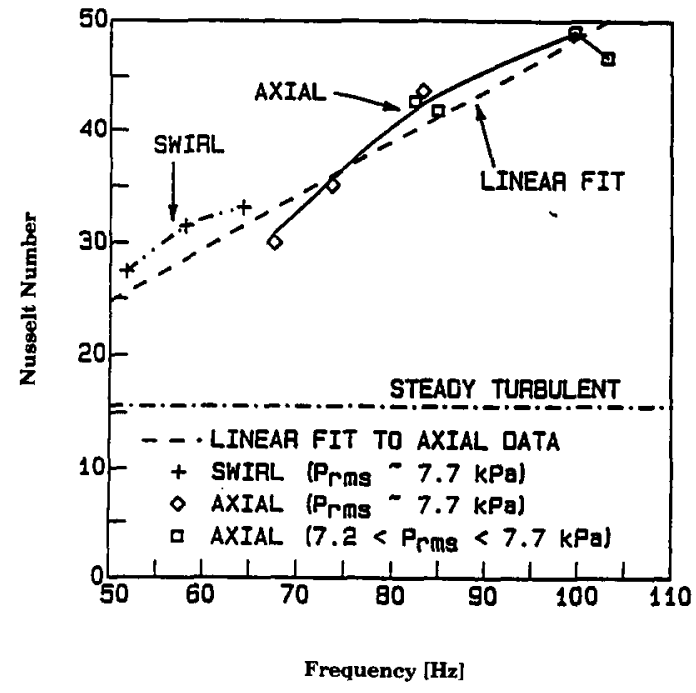

Fig. 12. Time- and space-averaged Nusselt numbers as a function of frequency at a combustion chamber pressure RMS $\left(p_{\text {RMS }}\right)$ of $7.7 \mathrm{kPa}$. Curves are cubic spline fits to data, and dashed line is a linear least-squares fit to the axial injection data. ${ }^{19}$

suggest

$$
N u=F\left[\left(\omega-\omega_{0}\right) U_{0}\right],
$$

where $\omega$ and $\omega_{0}$ are, respectively, the frequency and the minimum frequency for frequency enhancements effects, and $U_{0}$ is the velocity oscillation amplitude, which is directly proportional to $p_{\mathrm{RMS}}$.

A heat transfer correlation for a complex flow involving coherent oscillation (or pulsation) is difficult to construct solely on empirical grounds. This difficulty has been resolved by Arpaci et al. ${ }^{19}$ who follow a novel approach leading to a conceptual model based on the general principles and appropriate microscales of turbulence. Using this approach in recent studies, Arpaci, ${ }^{68-72}$ Arpaci and Tabaczynski, ${ }^{73}$ Arpaci and Selamet, ${ }^{74,75}$ and Arpaci and Dec ${ }^{76}$ have demonstrated a relationship between the appropriate microscales of turbulence and the transport processes in a number of forced and buoyancy-driven turbulent flows. Extending the approach to heat transfer in oscillating turbulent flows and utilizing the microscales reviewed in Section 5, Arpaci et al. ${ }^{19}$ suggest for the flow in the tailpipe of pulse combustors,

$$
\begin{gathered}
N u=0.028 \overline{\operatorname{Re}} \bar{s}^{3 / 4} \\
\times\left[1+0.21 \frac{U_{0}}{\bar{U}}\left(1+7.36 \frac{\left(\omega-\omega_{0}\right) D}{\bar{U}}\right)\right]^{3 / 4} .
\end{gathered}
$$

Here $\overline{R e}$ denotes the Reynolds number based on the mean velocity $\bar{U}, U_{0}$ denotes the amplitude of velocity oscillations, and $\left(\omega-\omega_{0}\right) D$ denotes the velocity related to the frequency $\omega$ of the oscillations, $\omega_{0}$ being the frequency below which quasi-steadiness holds $\left(\omega_{0}=46\right)$ for the present correlation, and $D$ being the hydraulic diameter of the tailpipe. The model is leastsquares fitted to the experimental data available in the 


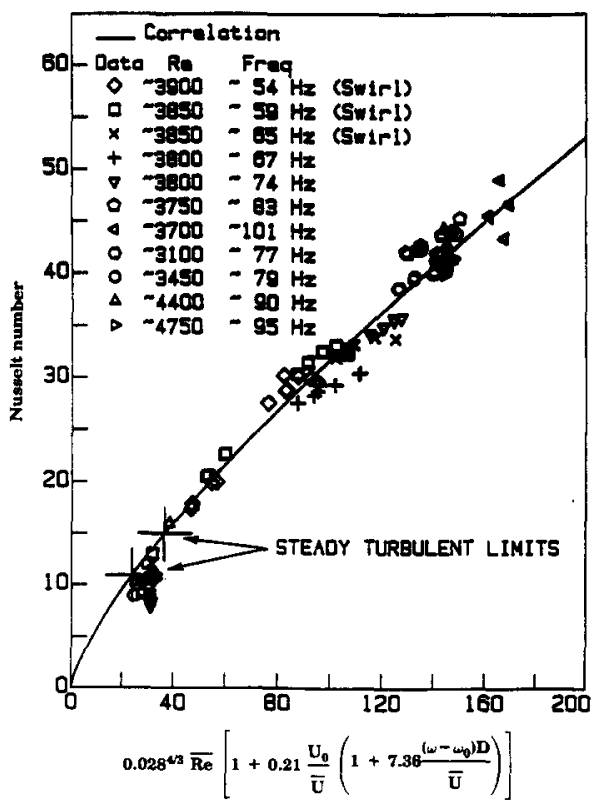

FiG. 13. A comparison of the experimental data with the correlation, Eq. (131). ${ }^{19}$

recent literature (Fig. 13). The agreement between the data and the model is remarkably good. The model is expected to be useful for pulse combustion systems of a variety of home and commercial heater applications. Equation (131) squared, in view of Eq. (74), is a measure for the thermal (entropic) efficiency of pulse combustor tailpipes.

\section{CONCLUSIONS}

The concept of lost heat is reviewed as opposed to that of lost work. It is shown that all forms of energy dissipated into heat describe the nonthermal part of entropy production while the heat energy dissipated into entropy describes the thermal part of this production. A dimensionless number for entropy production is introduced. This number is evaluated in terms of the first illustrative case which involves the entropy production (thermal efficiency) in the luminous zone of a quenched flame. The production is shown to be inversely proportional to the squared Peclet number. The tangency condition, usually considered in the literature to determine the minimum quench distance, is related to an extremum of entropy production. The distribution of entropy production between the flame and burner appears to remain constant for $\theta<$ $1-\theta_{u}$. This result is not surprising in view of the magnitude of the quench distance. The rapid and unusual change in distribution of entropy production for $\theta_{b} \geqslant 1-\theta_{u}$ is quite surprising and does not appear to be readily justifiable. This may well be a result of the nature of the models which for $\theta_{b}>$ $1-\theta_{u}$ begin to deviate from experimental results as shown in Ref. [26]. In the second illustrative case, the entropy production is evaluated in a radiation affected thermal boundary layer. This production is shown to be proportional to the squared Nusselt number. In the final case with contemporary industrial significance, a recent heat transfer correlation for the tailpipe of a pulse combustor is discussed. The square of this correlation, being proportional to entropy production, is a measure for the thermal efficiency of pulse combustion systems.

\section{REFERENCES}

1. ARPaCl, V. S., Conduction Heat Transfer, AddisonWesley, Reading, Massachusetts (1966).

2. ArPaCi, V. S. and Larsen, P. S., Convection Heat Transfer, Prentice-Hall, Englewood Cliffs, New Jersey (1984).

3. Bird, R. B., Stewart, W. E. and Lightfoot, E. N., Transport Phenomena, Wiley, New York (1960).

4. BejAN, A., Entropy Generation Through Heat and Fluid Flow, Wiley, New York (1982).

5. Bejan, A., Second Law analysis in heat transfer and thermal design, Advances in Heat Transfer, J. P. Hartnett and T. F. Irvine (Eds), Vol. 15, pp. 1-58 Academic Press, New York (1982).

6. BEJAN, A., Advanced Engineering Thermodynamics, Wiley-Interscience, New York (1988)

7. ARPACI, V. S., Radiative entropy production, $A I A A J$. 24, 1859-1860 (1986).

8. ARPACI, V. S. Radiative entropy production-lost heat into entropy, Int. J. Heat Mass Transfer 30, 2115-2123 (1987).

9. ARPACI, V. S., Foundations of entropy production Advances in Thermodynamics, S. Sieniutycz and P. Salomon (Eds), Taylor and Francis, New York (1990).

10. Arpaci, V. S. and Selamet, A., Radiative Entropy Production, Proc. 8th Int. Heat Transfer Conf., San Francisco, California, Vol. 2, pp. 729-734, C. L. Tien, V. P. Carey and J. K. Ferrell (Eds) (1986).

11. ArPaci, V. S. and Selamet, A., Entropy production in flames, Combust. Flame 73, 251-259 (1988).

12. Selamet, A. and ARPaCl, V. S., Entropy production in boundary layers, J. Thermophysics Heat Transfer 4, 404-407 (1990).

13. UNNo, W. and SPIEgEL, E. A., The Eddington approximation in the radiative heat equation, Publ. Astron. Soc. Jpn 18, 85-95 (1966).

14. Milne, E. A., Thermodynamics of Stars, Handbuch der Astrophysik, Vol. 3, Chap. 2, 65-255 (1930).

15. ArPaCI, V. S., Hookean and Stokesean implications of the radiative stress, Fundamentals of Thermal Radiation Heat Transfer ASME, HTD 40, 1-5 (1984).

16. Stratton, J. A., Electromagnetic Theory, McGrawHill, New York (1941).

17. Prager, W., Introduction to Mechanics of Continua, Ginn, pp. 87-92 (1961).

18. ARPACI, V. S. and GözÜM, D., Thermal stability of radiating fluids: The Bénard problem, Phys. Fluids 16, 581-588 (1973).

19. ArPaci, V. S., Dec, J. E. and Keller, J. O., Heat transfer in pulse combustor tailpipes, Proc. Int. Symp. Pulsating Combustion, Vol. 2 (Session F: Enhanced Heat and Mass Transfer), Monterey, CA (1991).

20. HirschFELDER, J. O. and CURTISS, C. F., The theory of flame propagation, J. Chem. Phys. 17, 1076-1081 (1949).

21. Hirschfelder, J. O. and Curtiss, C. F., Theory of propagation of flames. Part I: General equations, 3rd Symp. (Int.) Combust., pp. 121-127, Williams and Wilkins, Baltimore (1949).

22. Hirschfelder, J. O., Curtiss, C. F. and Campbell, D. E., The theory of flames and detonations, 4 th Symp. 
(Int.) on Combust., pp. 190-211, Williams and Wilkins, Baltimore (1953).

23. Botha, J. P. and Spalding, D. B., The laminar flame speed of propane/air mixtures with heat extraction from the flame, Proc. R. Soc. (Lond.) A225, 71-96 (1954).

24. KaSKAN, W. E., The dependence of flame temperature on mass burning velocity, 6 th Symp. (Int.) Combust., pp 134-143, Reinhold, New York (1957).

25. Ferguson, C. R. and Keck, J. C., On laminar flame quenching and its application to spark ignition engines, Combust. Flame 28, 197-205 (1977).

26. Ferguson, C. R. and KECK, J. C., Stand-off distances on a flat flame burner, Combust. Flame 34, 85-98 (1979).

27. Clarke, J. F. and McIntosh, A. C., The influence of a flameholder on a plane flame, including its static stability, Proc. R. Soc. (Lond.) A372, 367-392 (1980).

28. MCIntosh, A. C. and Clarke, J. F., A review of theories currently being used to model steady plane flames on flame-holders, Combust. Sci. Technol. 37, 201-219 (1984).

29. ARPACI, V. S. and TABACZYNSKI, R. J., Radiationaffected laminar flame propagation, Combust. Flame 46, 315-322 (1982).

30. ARPACI, V. S. and TABACZYNSKI, R. J., Radiationaffected laminar flame quenching, Combust. Flame 57, 169-178 (1984).

31. KOOKER, D. E., Numerical study of a confined premixed laminar flame: Oscillatory propagation and wall quenching, Combust. Flame 49, 141-149 (1983).

32. Sohrab, S. H. and Law, C. K., Extinction of premixed flames by stretch and radiative loss, Int. J. Heat Mass Transfer 27, 291-300 (1984).

33. LeE, K. Y. and Tien, C. L., Flame wall-quenching by radiation and conduction in combustion of condensed fuels, Combust. Sci. Technol. 43, 167-182 (1985).

34. Carrier, G. F., Fendell, F. E. and Bush, W. B., Stoichiometry and flameholder effects on a one-dimensional flame, Combust. Sci. Technol. 18, 33-46 (1978).

35. Clarke, J. F., On changes in the structure of steady plane flames as their speed increases, Combust. Flame 50 125-138 (1983).

36. Williams, F. A., Combustion Theory, 2nd Edn, Benjamin/Cummings, Menlo Park, California (1985).

37. Matkowsky, B. J. and Olagunu, D. O., Pulsations in a burner-stabilized premixed plane flame, SIAM J. Appl. Math. 40(3), 551-562 (1981).

38. YU, G., LAW, C. K. and WU, C. K., Laminar flame speeds of hydrocarbon + air mixtures with hydrogen addition, Combust. Flame 63, 339-347 (1986).

39. Egolfopoulos, F. N., Cho, P. and Law, C. K., Laminar flame speeds of methane-air mixtures under reduced and elevated pressures, Combust. Flame $\mathbf{7 6}$ 375-391 (1989).

40. KANURY, A. M., Introduction to Combustion Phenomena, Gordon and Breach Science, New York (1975).

41. Mullins, B. P., Experimental and theoretical studies of flammability, ignitibility and explosion prevention, Explosions, Detonations, Flammability and Ignition, Part II, S. S. Penner and B. P. Mullins (Eds), AGARDograph No. 31, Pergamon, New York (1959).

42. Westrrook, C. K. and Dryer, F. L., Chemical kinetic modeling of hydrocarbon combustion, Prog. Energy Combust. Sci. 10, 1-57 (1984).

43. Glassman, I., Combustion, 2nd Edn, Academic Press, Orlando, Florida (1987).

44. BirKan, M. A. and LAW, C. K., Asymptotic simulation of the four-step global kinetics of Hydrocarbon/Air mixtures under flow reactor conditions, Combust. Sci. Technol. 51, 145-207 (1987).

45. BirKan, M. A. and LAw, C. K., Asymptotic structure and extinction of diffusion flames with chain mechanism, Combust. Flame 73, 127-146 (1988).
46. Lin, T. H., LAw, C. K. and Chung, S. H., Theory of laminar flame propagation in off-stoichiometric dilute sprays, Int. J. Heat Mass Transfer 31(5), 1023-1034 (1988).

47. Egolfopoulos, F. N. and Law, C. K., Chain mechanisms in the overall reaction orders in laminar flame propagation, Combust. Flame 80, 7-16 (1990).

48. Peters, N. and Warnatz, J. (Eds), Numerical Methods in Laminar Flame Propagation, Vieweg \& Sohn, Braunschweig/Wiesbaden, Germany (1982).

49. CURLE, N., The Laminar Boundary Layer Equations, Clarendon, Oxford (1962).

50. LORD, H. A. and ARPACl, V. S., Effect of nongray thermal radiation on laminar forced convection over a heated horizontal plate, Int. J. Heat Mass Transfer 13 1737-1751 (1970)

51. Lentini, $M$. and Pereyra, V., An adaptive finite difference solver for nonlinear two point boundary problems with mild boundary layers, SIAM J. Numer. Anal. 14, 91-111 (1978).

Also IMSL manuals, Vol. 1, Ch. D, code: DVCPR (1982).

52. Hull, T. E., ENRIGHT, W. H. and JACKSON, K. R., User's guide for DVERK-a subroutine for solving non-stiff ODE's, TR No. 100, Department of Computer Science, University of Toronto (1976).

Also IMSL manuals, Vol. 1, Ch. D, code: DVERK (1982).

53. Özışık, M. N., Radiative Transfer, Wiley-Interscience, New York, Chap. 9 (1973).

54. Siegel, R. and Howel, J. R., Thermal Radiation Heat Transfer, 2nd Edn, Chap. 14, Hemisphere, Washington DC (1981).

55. Sparrow, E. M. and Cess, R. D., Radiation Heat Transfer, Chaps 7 and 10, Hemisphere, Washington DC (1978).

56. Alhaddad, A. A. and Coulman, G. A., Experimental and theoretical study of heat transfer in pulsecombustion heaters, Proc. Vol. I: Symp. Pulse Combust. Applic., GRI-82/0009.2, Atlanta, GA (Mar. 1982).

57. HanBy, V. I., Convective heat transfer in a gas-fired pulsating combustor, ASME J. Engr. Power 91, 48-52 (1969).

58. LiaO, N. S., WANG, C. C. and Hong, J. T., An investigation of heat transfer in pulsating turbulent pipe flow, Fundamentals of Forced and Mixed Convection, F. A. Kulacki and R. D. Boyd (Eds), HTD 42, ASME 23rd National Heat Transfer Conference, Denver, CO (1985).

59. GalitseyskiY, B. M. and RYZHov, YU. A., Heat transfer in turbulent gas flows in the case of high-frequency pressure fluctuations, Heat Transfer-Soviet Research 9(4), 178-183 (July-Aug. 1977).

60. Dec, J. E. and Keller, J. O., Pulse combustor tail-pipe heat-transfer dependence on frequency, amplitude, and mean flow rate, Combust. Flame 77, 359-374 (1989).

61. Keller, J. O., DeC, J. E., WestbrooK, C. K. and Bramlette, T. T., Pulse combustion: the importance of characteristic times, Combust. Flame 75, 33-44 (1989).

62. Keller, J. O., Westbrook, C. K., Bramlette, T. T. and DEC, J. E., Pulse combustion: The quantification of characteristic times, Combust. Flame 79, 151-161 (1990).

63. BARNETT, D. O. and VACHON, R. I., An analysis of convective heat transfer for pulsating flow in a tube, 4 th Int. Heat Transfer Conf. 3, Paris-Versailles, France (1970).

64. Stosic, N. and Hanjalic, K., Numerical study of unsteady convective heat transfer in pulsating duct flows, 7th Int. Heat Transfer Conf. 3, Munich, W. Germany (1982).

65. Martinelli, R. C., Boelter, L. M. K., Weinberg, E. B. and YAKAHI, S., Heat transfer to a fluid flowing period- 
ically at low frequencies in a vertical tube, $A S M E$ Trans. 65, 789-798 (1943).

66. KEIL, R. H. and BAIRD, M. H. I., Enhancement of heat transfer by flow pulsation, Ind. Eng. Chem. Process Des. Develop. 10, 473 (1971).

67. Dec, J. E., Keller, J. O. and Hongo, I., Time-resolved velocities and turbulence in the oscillating flow of a pulse combustor tail pipe, Combust. Flame, in press.

Also Sandia National Laboratories Report, SAND888844.

68. ArpaCl, V. S., Two heat transfer correlations via turbulent microscales, ASME Winter Annual Meeting, Seattle, WA, 83-WA/HT-14 (1983).

69. ARPaCI, V. S., Microscales of turbulence and heat transfer correlations, Int. J. Heat Mass Transfer 29, 1071-1078 (1986).

70. ArPaCI, V. S., Two thermal microscales for natural convection and heat transfer correlations, $A S M E$, HTD 60, 117-121 (1986).
71. ArPaCl, V. S., A thermal microscale via lost heat into entropy, ASME, HTD 80, 21-25 (1987).

72. ARPACI, V. S., Microscales of unsteady turbulent flows, APS 41st Annual Meeting, Buffalo, NY (1988).

73. ArPaCl, V. S. and TABaCZYNSKI, R. J., A NusseltReynolds, Prandtl relation in turbulent forced convection, ASME, National Heat Transfer Conference, Boston, MA, 83-HT-25 (1983).

74. Arpaci, V. S. and Selamet, A., The Pool Fire, The 23rd ASME National Heat Transfer Conference, Denver, Colorado. HTD. Vol. 45, Heat Transfer in Fire and Combustion Systems, C. K. Law, Y. Jaluria, W. W. Yuen and K. Miyasaka (Eds), 153-157 (1985).

75. Arpaci, V. S. and Selamet, A., Buoyancy driven turbulent diffusion flames, Combust. Flame 86, 203-215 (1991)

76. ArPaCl, V. S. and DEC, J. E., A theory for buoyancy driven turbulent flows, ASME, National Heat Transfer Conference, Pittsburgh, PA, 87-HT-5 (1987). 